\title{
CHARACTERIZING NATURAL-COLOR TYPE IIB BLUE DIAMONDS
}

\author{
By John M. King, Thomas M. Moses, James E. Shigley, Christopher M. Welbourn, \\ Simon C. Lawson, and Martin Cooper
}

\begin{abstract}
Although rarely encountered, blue diamonds are among the most famous, and most distinctive, of fine gemstones. To better understand these unique gems, more than 400 were studied at the GIA Gem Trade Laboratory over several years to reveal additional information about the relationships between their color, clarity, and other gemological properties. The overwhelming majority of natural-color blue diamonds are type IIb. The color appearance varies widely from light to dark, but there is a limited range of color saturation. As a result, color appearance between neighboring GIA GTL color grades can be subtle. Of the blue diamonds examined at GIA GTL, few had any solid inclusions. Nevertheless, internal features such as graining and color zoning can make the processing of these diamonds a challenge.
\end{abstract}

\section{ABOUT THE AUTHORS}

$\mathrm{Mr}$. King is laboratory projects officer, and Mr. Moses is vice president of Identification Services, at the GIA Gem Trade Laboratory in New York. Dr. Shigley is director of research at GIA in Carlsbad, California. Dr. Welbourn is head of Physics, Dr. Lawson is a research scientist in the Physics Department, and Mr. Cooper is research director, at De Beers DTC Research Centre, Maidenhead, United Kingdom.

Please see acknowledgments at end of article. This is a Carat Achievement article. Participating members of GIA Alumni \& Associates receive

two carat points for reading the article.

Gems \& Gemology, Vol. 34, No. 4, pp. 246-268 (C) 1998 Gemological Institute of America

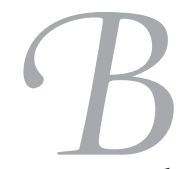

ecause of their great beauty and rarity, blue diamonds are both intriguing and highly valued (figure 1). Such important historic diamonds as the Hope, the Blue Heart (also called the Unzue or Eugénie Blue), and the Idol's Eye have greatly added to the fascination and mystery surrounding blue diamonds throughout history.

In recent years, auction sales have also placed blue diamonds in the forefront of industry interest. The current record per-carat price paid for a blue diamond at auction, $\$ 569,000$, was set in November 1995, for a 4.37 ct Fancy Deep blue oval shape which sold at Christie's Geneva. Only three diamonds have sold at auction for higher per-carat prices; indeed, of the 10 highest per-carat prices paid for colored diamonds at auction, six have been for blue diamonds (World Diamond Industry Directory e) Yearbook, 1997/98, p. 56).

Even with their high profile, blue diamonds have long been considered among the rarest of gems (Federman, 1989, 1998). The De Beers Polished Division, in their published compilation Important Diamond Auction Results 1997, noted only 18 blue diamonds offered for sale that year at the auction houses of Christie's, Sotheby's, and Phillips (in contrast to 143 predominantly yellow diamonds noted for the same period). Of the numerous colored diamonds submitted for grading reports to the GIA Gem Trade Laboratory (GIA GTL) during the first half of 1998, only $0.3 \%$ were described as predominantly blue. Although such diamonds are much sought after, dealers indicate that only a couple of new blue diamonds come to their attention during the course of a year (K. Ayvazian and I. Gol, pers. comm., 1998). This observation is consistent with the current mining recovery rate. Of all the De Beers South African rough production, there is on average "only one significant blue" mined per year. When they occur, such finds are said "to cause excitement along the chain from the discovery at the mine to the sorting" (M. Semple, pers. comm., 1998).

In GIA GTL's color grading of colored diamonds, there 
Figure 1. Blue diamonds are among the most highly prized objects in contemporary society. The connoisseur of such stones appreciates the subtle differences and nuances of color. Shown here

are a range of appearances

from the strongly colored heart shape in the ring to the gray-blue marquise shape at the upper left. The diamonds range from $0.48 \mathrm{ct}$ to $2.01 \mathrm{ct}$; the $1.04 \mathrm{ct}$ blue diamond in the ring is surrounded by approximately 2 carats of near-colorless diamonds.

Loose stones courtesy of Rima Investors Corp.; the ring is courtesy of Martin Kirschenbaum Trading, Inc. Composite photo (C) Harold e) Erica Van Pelt.

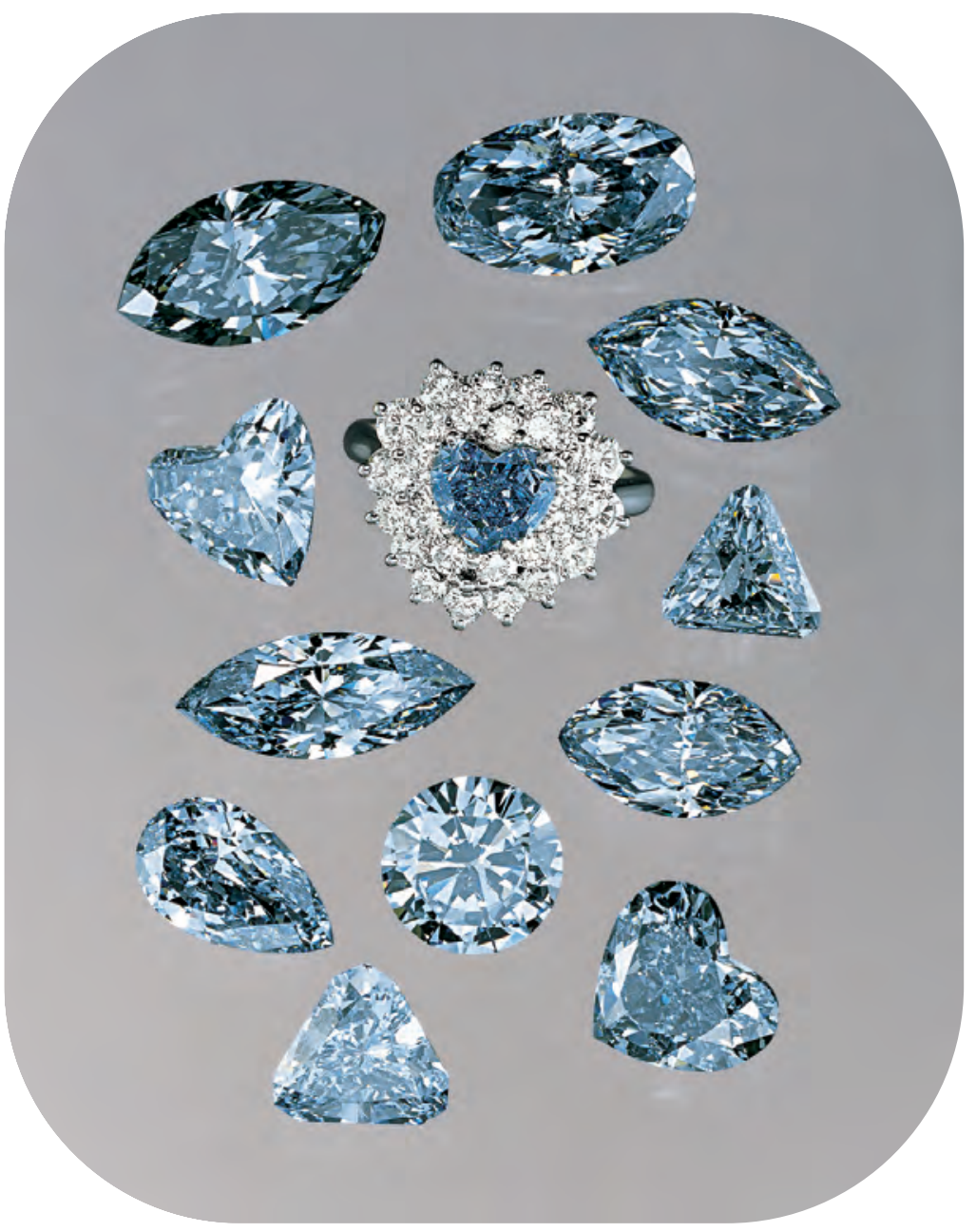

are other natural colors that are more rarely encountered than blue (such as purple or red). However, it is the combination of relative rarity (although the numbers are small, they are sufficient to enable a recognized market to be established), high value, and trade enthusiasm that makes it critical to expand our knowledge of blue diamonds. In particular, precisely because blue diamonds are so rare, few dealers understand their full range of color appearances. This is important to accurately assess the relationship of one blue diamond to another. As is the case with other aspects of diamond valuation, subtle differences in color appearance (reflected in differences in grading terminology| ${ }^{*}$ can result in large differences in value. Therefore, understanding and consistently describing color in blue diamonds is critical.

To this end, GIA GTL and GIA Research have been compiling for several years (as well as drawing on the Laboratory's more than 40 years of reporting on these stones) information based on a significant quantity of blue diamonds they have graded and/or otherwise documented. This study represents the largest number of blue gem diamonds ever examined by a single organization, including some of the most famous diamonds known.

Following a discussion of the history of blue diamonds and a mention of some of the main localities where they are found, the present article reports on the relationship of the various color appearances of blue diamonds, as reflected in their GIA GTL color grades, to their other gemological properties.

\footnotetext{
*Note that this article contains a number of photos illustrating subtle distinctions in color. Because of the inherent difficulties of controlling color in printing (as well as the instability of inks over time), the color in an illustration may differ from the actual color of the diamond.
} 
He sold this rough diamond to Louis XIV of France in 1669 , who had the diamond cut into a triangular shape of 67.12 ct (possibly with additional smaller cut stones). In 1792, during the French Revolution, this and other diamonds were stolen from the collection of the French Crown Jewels housed in the Garde Meuble palace. It is believed that, to avoid detection, subsequent owners had the Tavernier Blue recut twice, ultimately to a weight of $45.52 \mathrm{ct}$, before Henry Philip Hope purchased it in 1830 (figure 2). Currently on exhibit in the Harry Winston gallery at the Smithsonian Institution in Washington, DC, the Hope diamond is seen by more than four million museum visitors each year (J. E. Post, pers. comm., 1998).

The $70.21 \mathrm{ct}$ Idol's Eye is also reported to have been found in the Golconda district in the early 17 th century. Like the Hope, it is a classic example of a diamond with a history surrounded by myths and legends (Krashes, 1993). It was claimed to have been set in the eye of an idol in the Temple of Benghazi, rumored to have been seized from its original owner for payment of debts, and disappeared for 300 years before resurfacing. This light blue diamond was rediscovered in the possession of Abdul Hamid II (1842-1918) in 1906, who became the 34th Ottoman Sultan.

A number of other important blue diamonds have published histories (see, for example, Balfour, 1997) and specific names that have lasted for many years. Table 1 presents a list of some of these notable blue diamonds, with their weights, color descriptions, cut shapes, and the most recent year that individual stones were examined by GIA staff members.

Today, there is little production at the Indian mines. The Premier mine in South Africa is now considered the most significant source of the blue diamonds entering the market (Federman, 1989; G. Penny, pers. comm., 1998).

The Premier Mine. Discovered in 1903, the Premier mine was initially worked by open-pit methods (figure 3); in 1905, it yielded the largest rough diamond ever found, the 3,106 ct Cullinan. In celebration of the gift of this diamond to King Edward VII of England, Thomas Cullinan, then chairman of the Premier mine, presented his wife with a necklace that contained several blue diamonds, including a $2.60 \mathrm{ct}$ center stone (illustrated in Janse, 1995, p. 240).

The open-pit operations were closed in 1932, but De Beers reopened the Premier in 1946 as an under- 
ground mine, with full production attained in 1949. Underground operations continue to the present time (figure 4).

Since mining began at the Premier in 1903, 278 million tons of ore have been processed and 90.5 million carats of gem and industrial diamonds recovered. Current production is approximately 1.6 million carats per year. The yield is 50 carats per 100 tons of ore, or approximately $0.50 \mathrm{ct}$ per ton. Of this production, diamonds with any evidence of blue color (but that would not necessarily color grade as blue once cut and polished) represent less than $0.1 \%$ (H. Gastrow, pers. comm., 1998). The Premier mine is well known as a source not only of blue diamonds, but also of large, colorless diamond crystals. Indeed, it is the three or four blue and/or colorless "specials" recovered each year that make the Premier mine a viable operation (G. Penny, pers. comm., 1998). To date, there is no known correla- tion between the geologic conditions of the host rock and the type or color of diamond recovered from the Premier mine or elsewhere; the recovery of blue diamonds is random and very sporadic (D. E. Bush, pers. comm., 1998).

Other South African mines that have produced blue diamonds include the Jagersfontein and Koffiefontein (both near Kimberley); the Bellsbank mine near Barkly West; and the Helem mine at Swartsruggens. Very rarely, blue diamonds have been found in alluvial deposits at Lichtenburg in the Western Transvaal. Guinea, in western Africa, is also known to have produced blue diamonds (Webster, 1994). Historically, central Africa has been rumored to be a source of blue diamonds, especially Sierra Leone for lighter blues (A. Arslanian, pers. comm., 1997). Outside of Africa, blue diamonds have been reported from Kalimantan on the island of Borneo in Indonesia (Spencer et al., 1988),

\begin{tabular}{|c|c|c|c|c|}
\hline Name & $\begin{array}{l}\text { Weight } \\
\text { (carats) }\end{array}$ & Color description ${ }^{b}$ & Shape & $\begin{array}{l}\text { Date of the most recent } \\
\text { GIA Gem Trade Laboratory } \\
\text { report/examination }\end{array}$ \\
\hline Brazilia & 176.2 & "light blue" & Rough & $n e^{e}$ \\
\hline Idol's Eye & 70.21 & Light blue & Modified triangle & 1995 \\
\hline Mouawad Blue & 49.92 & Fancy Dark blue & Pear & 1984 \\
\hline Copenhagen Blue & 45.85 & "blue" & Emerald & ne \\
\hline $\mathrm{Hope}^{\mathrm{c}}$ & 45.52 & Fancy Deep grayish blue & Cushion & 1996 \\
\hline Tereschenko & 42.92 & "blue" & Pear & ne \\
\hline Graff Imperial Blue & 39.31 & Fancy Light blue & Pear & 1984 \\
\hline Wittlesbach & 35.50 & "blue" & Oval & ne \\
\hline Sultan of Morocco & 35.27 & "bluish gray" & Cushion & ne \\
\hline North Star & 32.41 & "blue" & Pear & ne \\
\hline Blue Heart (Unzue Blue) ${ }^{c}$ & 30.62 & Fancy Deep blue & Heart & 1997 \\
\hline Blue Lili & 30.06 & Fancy blue & Cushion & 1980 \\
\hline Transvaal Blue & 25.00 & "blue" & Pear & ne \\
\hline Howeson & 24 & "blue" & $\mathrm{nr}^{\mathrm{d}}$ & ne \\
\hline Begum Blue ${ }^{c}$ & 13.78 & Fancy Deep blue & Heart & 1995 \\
\hline Brunswick Blue & 13.75 & "blue" & Pear & ne \\
\hline Graff Blue & 6.19 & Fancy Dark blue & Round & 1990 \\
\hline Marie Antoinette Blue & 5.46 & "blue" & Heart & ne \\
\hline Cullinan Blue necklace (center stone) & 2.60 & "blue" & Cushion & 1993 \\
\hline
\end{tabular}

a Information obtained from GIA GTL reports or examination of individual diamonds (as indicated by a date given in the last column), as well as from the GIA Diamond Dictionary (1993), Christie's Jewellery Review 1995 (1996), and Balfour (1997).

${ }^{b}$ Color descriptions for diamonds graded by GIA GTL (i.e., those that are not set off by quotation marks) represent the color grading terminology that prevailed at that time. Modifications to the GIA GTL colored diamond color grading system and its nomenclature were introduced in 1995.

${ }^{c}$ Diamonds that were examined as part of this study.

${ }^{d} n r=$ not recorded.

${ }^{e}$ ne $=$ not examined. 
diamonds are rarely described as simply "blue" (without a modifier) in the GIA GTL grading system. Those non-IIb diamonds that are described as "blue" represent a miniscule number of the blue diamonds examined in GIA GTL. For these reasons, they are not part of this study. In addition, because the overwhelming majority of diamonds described as blue by GIA GTL are natural-color type $\Pi \mathrm{Ib}$, this article deals only briefly with their separation from treated-color diamonds. (The latter are typically green-blue, not blue, and are never electrically conductive). Likewise, although gem-quality synthetic type IIb blue diamonds have been produced experimentally (Crowningshield, 1971), they are not commercially available. Therefore, they are not a significant part of this study either.

Some information on blue diamonds is presented in books by, for example, Liddicoat (1987, p. 230), Webster (1994), and Hofer (1998). A brief summary of the gemological properties of natural-color type IIb blue diamonds was presented as part of a natu$\mathrm{ral} /$ synthetic diamond identification chart by Shigley et al. (1995). To date, however, we know of no previous systematic study in which the gemological characteristics of a large number of blue diamonds have been documented.

\section{MATERIALS AND METHODS}

Samples. Over the course of the past 40 years, and in particular during the 1990s, staff members at the GIA Gem Trade Laboratory and GIA Research have examined hundreds of natural-color type IIb blue diamonds. For the present study, we gathered data from a representative sample of more than 400 of these diamonds, each of which was described as predominantly blue (i.e., blue, grayish blue, and grayblue), to explore their color relationships with each other and with their gemological properties. The polished diamonds ranged from 0.07 to 45.52 ct 165 weighed more than $5 \mathrm{ct}$ ). Based on their infrared spectra and/or electrical conductivity, the diamonds in this study were all type $\mathrm{Ib}$. Because of time constraints or other restrictions, it was not possible to gather all data on all of the blue diamonds included in this study. Some data (such as duration of phosphorescence) are not typically recorded in the course of routine gemological testing, as it is the absence or presence of the phenomenon that is most relevant. In specific cases, some tests could not be performed due to the conditions under which we were required to grade. For example, we typically cannot perform comprehensive testing (e.g., for the Hope diamond) when the grading must be done off the GIA GTL premises. Also, because GIA GTL offers different reporting services for colored diamonds, different data are captured for different stones. For example, laboratory clients do not request a clarity grading on all colored diamonds. Consequently, we collected data on random subsets of blue diamonds for some properties (e.g., duration of phosphorescence). The number of stones examined for some key characteristics are listed in table 2; other sample numbers are given in the Results section.

Grading and Testing Methods. We used standard GIA GTL colored diamond color-grading methodology to determine the color descriptions and rela-

Figure 4. Since 1946, the Premier mine has been operated underground. The occasional recovery of blue diamonds helps make the expensive underground mining viable. Photo courtesy of De Beers.

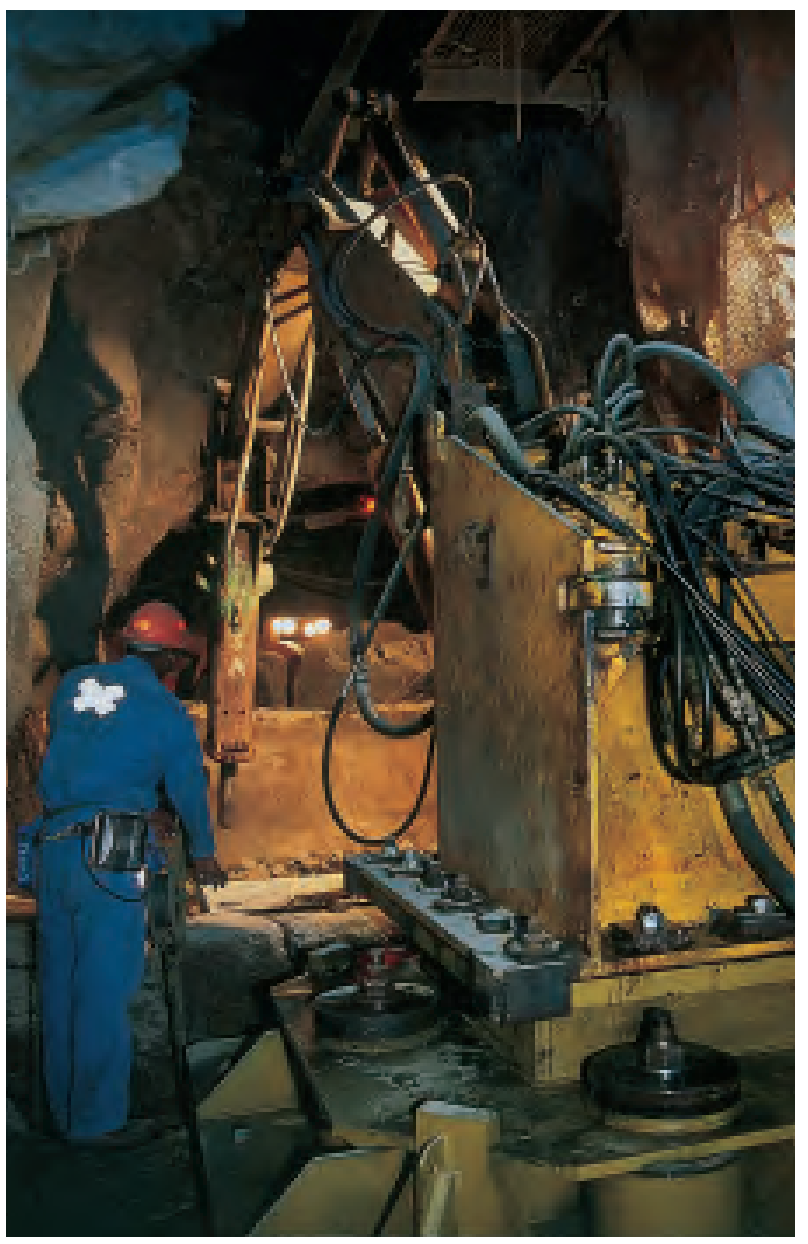




\section{Box A: The Physics of Blue Type IIb Semiconducting Diamonds}

The classification "type IIb" was suggested by Custers (1952) for type II diamonds that displayed phosphorescence after excitation with short-wave UV radiation. He noted that these diamonds also showed higher electrical conductivity than usual. The diamonds studied in this initial work were described as "water white" or light brown. However, in a note, Custers mentioned that similar characteristics had been seen in a diamond that was "a diluted bluish color." Further work by Custers (1954) showed that blue diamonds did indeed consistently exhibit high electrical conductivity and phosphorescence.

It was initially believed that the impurity responsible for the characteristic features of type IIb diamonds was aluminum (Austin and Wolfe, 1956; Dean et al., 1965; Lightowlers and Collins, 1966). However, when Wentorf and Bovenkerk (1962) produced synthetic diamonds doped with boron, they found that depth of blue color increased with boron content. They proposed that boron was responsible for the characteristic features of type IIb diamonds. Subsequently, Collins and Williams (1971) and Chrenko (1973) found that aluminum concentrations could not account for type IIb characteristics in diamonds, whereas Chrenko (1973) and Lightowlers and Collins (1976) showed that there was a good correlation between boron concentra- tion and electrical conductivity in diamonds.

Electrical measurements (Leivo and Smoluchowski, 1955; Custers, 1955; Brophy, 1955; Austin and Wolfe, 1956; Dyer and Wedepohl, 1956; Wedepohl, 1956; Collins and Williams, 1971) showed that type IIb diamonds behave as semiconductors: The electrical conductivity increases with increasing temperature. These measurements also revealed that the conductivity is $p$-type. In $p$-type semiconductors, electrical current is carried by positively charged "holes," whereas in $n$-type semiconductors it is carried by negatively charged electrons.

A "hole" is what is left behind when an electron is missing from the normal bonding structure of a semiconductor. If an electron moves in to fill the hole, then another hole is left at that electron's original position. Although it is actually the negatively charged electron that has moved, the effect is the same as if a positively charged hole had moved in the opposite direction. Holes result when impurities known as acceptors are present. An acceptor can "accept" an electron from the bonding structure of the semiconductor, leaving a hole behind. In diamonds, boron acts as an acceptor; a boron atom contributes only three electrons to the bonding structure of the diamond crystal, whereas a carbon atom contributes four electrons (thus there is a deficiency of one electron per boron atom).

Figure A-1. The UV-Vis-IR spectrum of a natural type IIb diamond is shown in blue and, for comparison, that of a natural type II a diamond is in red. The IR absorption of the type IIb below $1332 \mathrm{~cm}^{-1}$ results from lattice vibrations induced by boron impurities. The bands at 2455, 2802, and $2928 \mathrm{~cm}^{-1}$ are due to transitions of holes from the ground state to excited states of the boron acceptors. The absorption starting at $2985 \mathrm{~cm}^{-1}$ and continuing with decreasing intensity into the visible range corresponds to electrons being excited from the valence band to neutral acceptors. The fact that this absorption extends into the visible part of the spectrum, and decreases in intensity from the red end toward the blue end, gives rise to the blue color in type IIb diamonds.

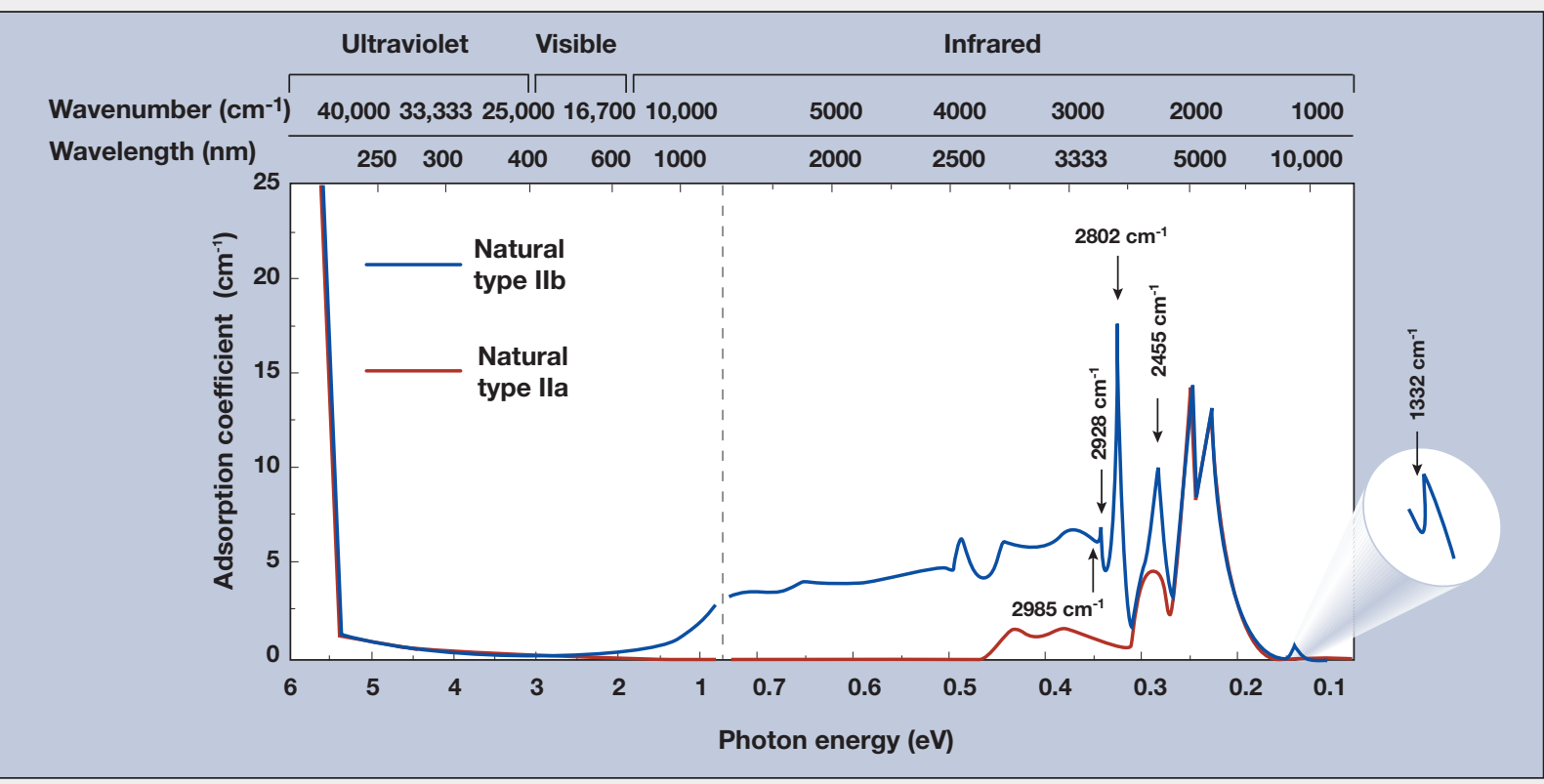


Analysis of the electrical measurements cited above implied that not all of the boron acceptors present in diamonds contribute to the semiconducting behavior. Even in type II diamonds, there are sufficient concentrations of nitrogen (although typically less than $0.1 \mathrm{ppm}$ ) to influence the electrical behavior. Nitrogen, which contributes five electrons to the bonding structure of a diamond crystal, acts as an electron donor. They donate electrons to boron acceptors, which become permanently ionized. These acceptors are said to be "compensated" by an electron from the nitrogen. Only the uncompensated acceptors contribute to semiconductivity, so the strength of this behavior depends on the difference between the boron and nitrogen concentrations, not on boron concentration alone.

The blue color of type IIb diamonds results from the decreasing edge of a region of absorption that is centered in the infrared and extends into the visible region of the spectrum. In addition to the intrinsic absorption exhibited by all diamonds, the infrared spectrum of type IIb diamonds, when measured at room temperature, has a series of bands located at 2455, 2802, and $2928 \mathrm{~cm}^{-1}$ (figure A-1). These bands were first observed by Blackwell and Sutherland (1949). Austin and Wolfe (1956) and Wedepohl (1957) found that their intensity is related to the concentration of neutral (i.e., uncompensated) boron acceptors. Smith and Taylor (1962) found that when the infrared spectrum was recorded at low temperature $\left(-188^{\circ} \mathrm{C}\right)$, it was evident that these bands were composed of numerous sharp lines, the details of which are still not completely understood.

The basic shape of this spectrum can be explained in terms of the energy-level diagram shown in figure A2. The energy level of the boron acceptor is located 0.37 electron volts $(\mathrm{eV})$ above the valence band. The continuum absorption above $2985 \mathrm{~cm}^{-1}$ results from the capture of electrons by boron acceptors at various depths in the valence band; this leaves holes in the valence band that can take part in electrical conduction, a process called photoconduction. Thermal stimulation of electrons from the valence band onto the acceptors also results in holes in the valence band being available for electrical conduction. The higher the temperature, the greater the number of acceptors that are ionized, the greater the number of holes in the valence band, and so the higher the electrical conductivity will be.

Phosphorescence in boron-doped synthetic diamond has recently been studied in some detail. Whereas natural type IIb diamonds are known to exhibit both red and blue phosphorescence, synthetic type IIb diamonds always exhibit blue phosphorescence, occasionally accompanied by orange. Both may exhibit a greenish blue fluorescence when excited by electrons (cathodoluminescence) or short-wave UV radiation. This luminescence has been attributed to transitions between a donor and the boron acceptor, where the donor is believed to be nitrogen related (see Klein et al., 1995). It has been observed that whereas the fluorescence is also a characteristic of diamonds that have been so heavily boron doped as to be very dark blue or black, the phosphorescence is only dominant and long lived in lightly boron-doped diamonds (containing less than about $10 \mathrm{ppm}$ of uncompensated boron and appearing pale blue to dark blue).

Watanabe et al. (1997) have proposed a model to explain this phosphorescence behavior. Essentially, their recombination model shows that following shortwave UV excitation and the rapid fluorescence decay, the rate of electron transition from the donor to the boron acceptor is limited by the availability of holes in the valence band. At room temperature, only about $0.2 \%$ of the boron acceptors are ionized; the lower the concentration of these acceptors is, the lower is the probability that the donor-to-acceptor transition can occur. Such low-probability transitions are characterized by long decay times, so strong, long-lived phosphorescence is a characteristic only of lightly borondoped material. Boron concentrations in natural type $\mathrm{IIb}$ diamonds are usually a few ppm at most, and often considerably less than this, so their phosphorescence behavior is similar to that of the lightly boron-doped synthetic diamonds.

Figure A-2. In this schematic energy-level diagram for the boron acceptor in diamond, the acceptor ground state is located $0.37 \mathrm{eV}$ above the top of the valence band. The excited-state energy levels are shown in simplified form for clarity. In fact, they are split into a number of sublevels. Bound-hole transitions from the ground state to these excited states give rise to the bands in the infrared spectrum at 2455, 2802, and $2928 \mathrm{~cm}^{-1}$. If a hole is excited from the acceptor ground state into the valence band, either thermally or by photons of energy greater than $0.37 \mathrm{eV}$, it becomes available for electrical conduction.

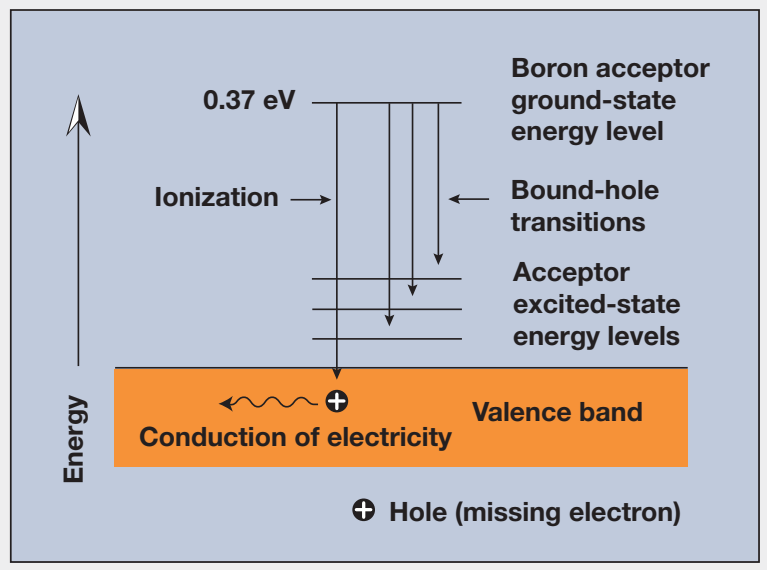


TABLE 2. Clarity, phosphorescence, and electrical conductivity of blue diamonds as they relate to GIA Gem Trade Laboratory color grades. $^{\text {a }}$

\begin{tabular}{|c|c|c|c|c|c|c|c|c|c|c|c|c|c|c|c|c|c|c|c|c|}
\hline \multicolumn{2}{|c|}{$\begin{array}{l}\text { GIA GTL } \\
\text { color grade }\end{array}$} & \multicolumn{5}{|c|}{ Clarity } & \multicolumn{6}{|c|}{$\begin{array}{l}\text { SW UV phosphorescence } \\
\text { intensity }\end{array}$} & \multicolumn{8}{|c|}{$\begin{array}{l}\text { SW UV phosphorescence duration } \\
\text { (seconds) }\end{array}$} \\
\hline Grade & No. & $\mathrm{FL} / \mathrm{IF}$ & VVS & VS & $\mathrm{SI} / \mathrm{I}$ & No. & None & Wh & Med & St & VSt & No. & $<5$ & $6-15$ & $16-25$ & $26-35$ & $36-45$ & $45+$ & Avg & No. \\
\hline Faint & 9 & 2 & 3 & 0 & 4 & 9 & 0 & 1 & 1 & 0 & 0 & 2 & - & - & - & - & - & - & - & 0 \\
\hline Very Light & 10 & 2 & 2 & 2 & 3 & 9 & 0 & 2 & 1 & 0 & 1 & 4 & - & - & - & - & - & - & - & 0 \\
\hline Light & 27 & 5 & 3 & 6 & 3 & 17 & 1 & 7 & 4 & 0 & 0 & 12 & 2 & 0 & 0 & 1 & 0 & 0 & 12 & 3 \\
\hline Fancy Light & 44 & 3 & 6 & 7 & 5 & 21 & 2 & 16 & 0 & 0 & 0 & 18 & 4 & 2 & 1 & 0 & 0 & 0 & 6 & 7 \\
\hline Fancy & 226 & 35 & 28 & 55 & 18 & 136 & 5 & 70 & 16 & 2 & 1 & 94 & 9 & 6 & 2 & 0 & 0 & 0 & 8 & 17 \\
\hline Fancy Intense & 84 & 29 & 12 & 14 & 9 & 64 & 1 & 14 & 3 & 0 & 0 & 18 & 8 & 1 & 0 & 1 & 0 & 0 & 7 & 10 \\
\hline Fancy Dark & 10 & 1 & 2 & 0 & 0 & 3 & 1 & 3 & 1 & 0 & 0 & 5 & 1 & 2 & 0 & 0 & 0 & 0 & 6 & 3 \\
\hline Fancy Deep & 46 & 6 & 7 & 12 & 5 & 30 & 4 & 12 & 4 & 1 & 0 & 21 & 1 & 3 & 0 & 1 & 1 & 0 & 18 & 6 \\
\hline Fancy Vivid & 6 & 3 & 0 & 2 & 0 & 5 & 0 & 5 & 1 & 0 & 0 & 6 & 2 & 4 & 0 & 0 & 0 & 0 & 8 & 6 \\
\hline Totals & 462 & 86 & 63 & 98 & 47 & 294 & 14 & 130 & 31 & 3 & 2 & 180 & 27 & 18 & 3 & 3 & 1 & 0 & - & 52 \\
\hline
\end{tabular}

a Abbreviations: No. = number of samples tested in each subcategory, Wk $=$ weak, Med $=$ medium, St $=$ strong, VSt $=$ very strong, Avg = average. The clarity grade ranges follow the standard GIA GTL system for clarity grading of diamonds.

tionships of the study diamonds (see King et al., 1994). We have continued to look into instrumental measurement to assist in color determinations. To date, however, we have not identified instrumentation that can adequately describe the complex faceup color appearance of a colored diamond with the perspective that an experienced observer can pro-

Figure 5. Three categories of diamonds have been associated with a natural blue color: (1) type IIb, which are colored by boron impurities; (2) those type Ia or II a that owe their color to radiation exposure; and (3) those type Ia in which the color is associated with hydrogen. Of these, only type IIb diamonds (like that in the center) are typically described as blue (without a hue modifier) in the GIA GTL colored diamond color-grading system. Those naturally colored by exposure to radiation are usually described as green-blue (left), whereas those colored by color centers associated with hydrogen are described as grayviolet to gray-blue (right). The photo of the $1.01 \mathrm{ct}$ blue marquise is by Shane F. McClure; those of the $0.28 \mathrm{ct}$ gray-violet heart shape and the $0.15 \mathrm{ct}$ greenblue round brilliant are by Robert Weldon.

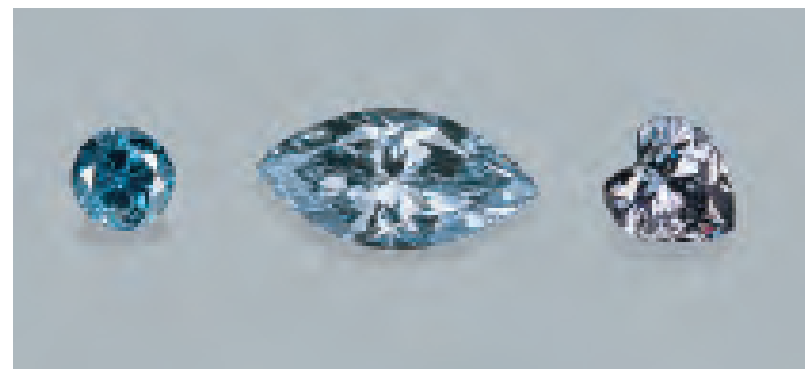

vide in a controlled grading environment such as that used in our laboratory.

Standard equipment was used for gemological documentation, including a Gemolite Mark VII binocular gemological microscope, a GIA GEM Instruments ultraviolet unit with long-wave (365 $\mathrm{nm})$ and short-wave $(254 \mathrm{~nm})$ lamps, a desk-model spectroscope, and a GIA GEM Instruments conductometer. Electrical conductivity measurements were made by placing the diamond on a metal base plate and touching a probe carrying an electric current to various surfaces of the polished diamond. Because we found that in some diamonds the measured conductivity values varied from one location to the next, we made several measurements on each stone and recorded the highest conductivity reading in our database. When documenting conductivity and reporting the results here, we used a numerical value that expresses the electrical current that passed through the diamond relative to the current measured when the probe was touched to the metal base plate (which, in this study, was always 135). This was also done to compensate for minor variations in line current. Because of the difficulty of making good, consistent contact between the instrument and the diamond, these values do not represent a precise measurement of the electrical conductivity. At best, they provide a relative indication of differences in conductivity among the blue diamonds tested.

A Hitachi U-4001 spectrophotometer was used to collect visible absorption spectra, from $400 \mathrm{~nm}$ to $800 \mathrm{~nm}$, at low (liquid nitrogen) temperatures. To 


\begin{tabular}{|c|c|c|c|c|c|c|c|}
\hline \multicolumn{7}{|c|}{$\begin{array}{l}\text { Electrical conductivity } \\
\text { values }^{\mathrm{b}}\end{array}$} & \multirow{2}{*}{$\begin{array}{c}\text { GIA GTL } \\
\text { color grade } \\
\text { Grade }\end{array}$} \\
\hline $10-30$ & $31-50$ & $51-70$ & $71-90$ & $90_{+}$ & Avg & No. & \\
\hline - & - & - & - & - & - & 0 & Faint \\
\hline - & - & - & - & - & - & 0 & Very Light \\
\hline 3 & 4 & 2 & 0 & 0 & 41 & 9 & Light \\
\hline 4 & 7 & 11 & 3 & 1 & 56 & 26 & Fancy Light \\
\hline 12 & 31 & 35 & 17 & 8 & 60 & 103 & Fancy \\
\hline 3 & 7 & 7 & 8 & 3 & 64 & 28 & Fancy Intense \\
\hline 0 & 0 & 5 & 2 & 1 & 76 & 8 & Fancy Dark \\
\hline 1 & 3 & 6 & 6 & 6 & 77 & 22 & Fancy Deep \\
\hline 2 & 1 & 1 & 1 & 1 & 62 & 6 & Fancy Vivid \\
\hline 25 & 53 & 67 & 37 & 20 & - & 202 & Totals \\
\hline
\end{tabular}

${ }^{b}$ All 462 samples were electrically conductive.

investigate the relationship between the depth of color and the visible absorption spectra, we selected four diamonds of similar size and shape but different depths of blue color (GIA GTL grades Very Light, Fancy Light, Fancy, and Fancy Intense). We also tested a Fancy Light gray diamond for comparison. We recorded the spectrum of each diamond with the light directed into a bezel facet and emerging from the pavilion facet on the opposite side. We then corrected the measured absorbance values for the approximate size of the diamond. Light passing through a diamond does not follow a straight path without any internal reflections, and a large portion of the diamond is illuminated in the instrument. Therefore, to simulate the direction and length of the light path through the diamond, we calculated an approximate sample thickness as the average of the girdle width and the table-to-culet thickness.

For the purposes of this study, infrared absorption spectra were recorded with a Nicolet Model 510 FTIR spectrometer over a range of 6000 to 400 wavenumbers $\left(\mathrm{cm}^{-1}\right)$ on the same five diamonds for which visible spectra were recorded. Laser Raman microspectrometry and energy-dispersive X-ray fluorescence (EDXRF) analysis were attempted to identify the inclusions in two other blue diamonds.

\section{RESULTS}

Color Appearance. One of the most important parts of this study was the unique opportunity to document the range of color appearances of blue diamonds. The study samples covered the entire range of GIA GTL fancy grades, as shown in figure 6.
Details of the hue (such as blue in this case), tone (the lightness or darkness of a color), and saturation (the strength of a color) of the diamonds-that is, their location in color space-are described below (again, for details on this color-grading system, see King et al., 1994).

Hue. The diamonds in this study typically occur in a restricted region of the hue circle (figure 7). This supports our past observations that the hue of type IIb blue diamonds does not transition smoothly into the neighboring color hues (i.e., their hue does not extend into violetish blue in one direction around the hue circle, or into greenish blue in the other direction). Within this region of the hue circle, there are two narrow populations. The fact that type IIb blue diamonds occur within such narrow ranges is very different from the situation with yellow diamonds, in which subtle hue shifts are seen throughout its hue range.

Tone and Saturation. Figure 8 shows the general location of the blue diamonds in our study on a tone and saturation grid. Of the three color attributes, blue diamonds showed the greatest variation in tone: The samples covered a broad light-todark range.

Compared to other colors in diamond, however, a relatively narrow range of appearance distinctions was seen for the saturation of blue diamonds. For example, at its widest region-i.e., corresponding to such GIA GTL fancy grades as Fancy, Fancy Intense

Figure 6. This pie chart illustrates the percentages of the 462 blue diamonds studied that appeared in each GIA GTL fancy grade category.

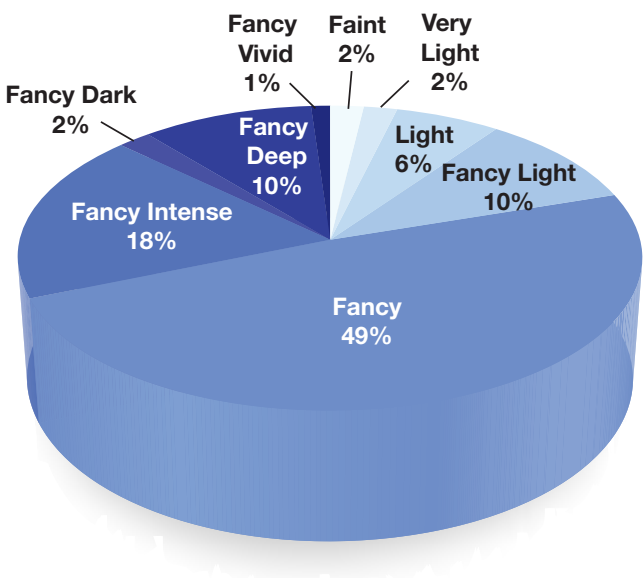

GEMS \& GEMOLOGY Winter 1998 


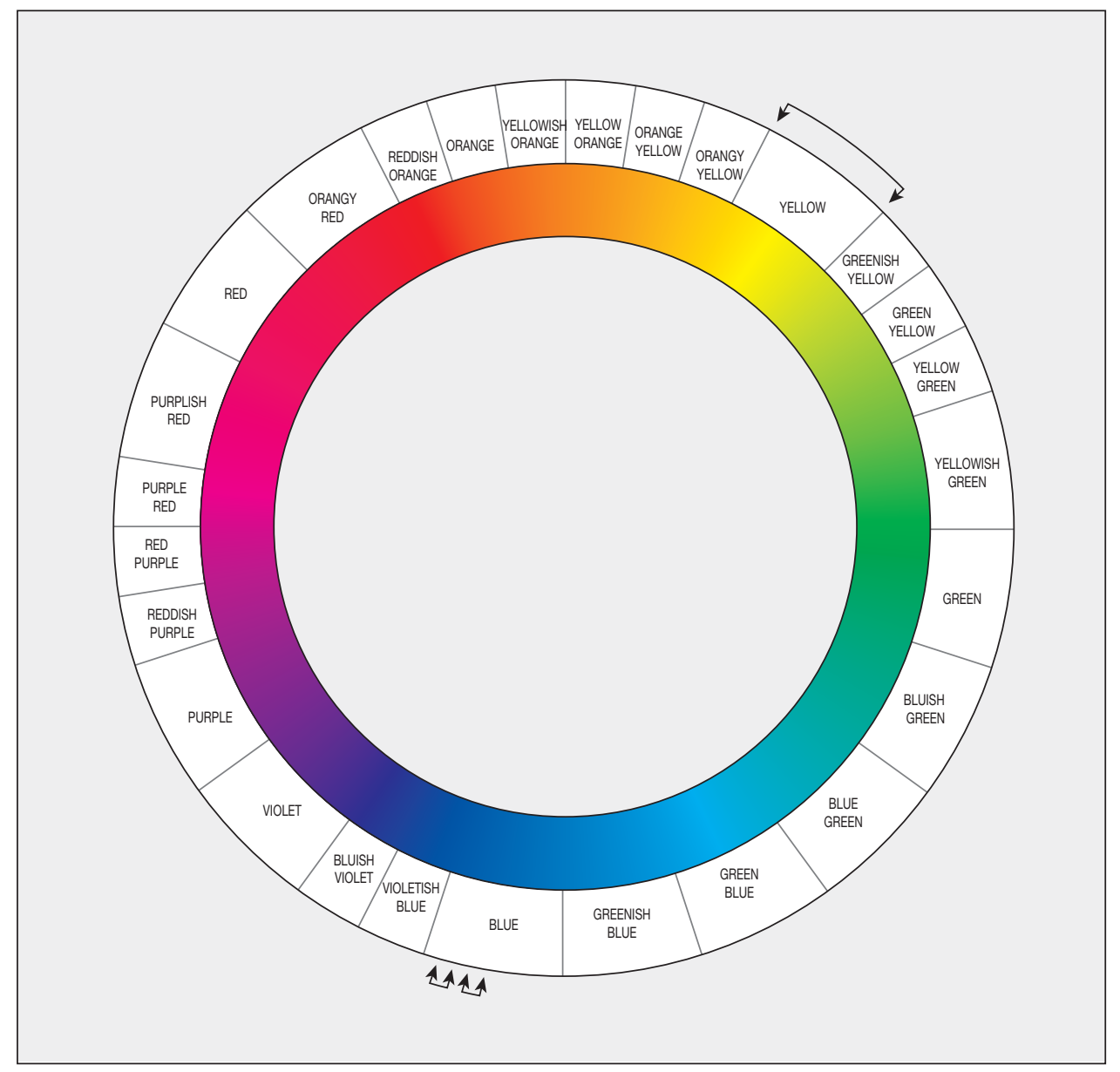

Figure 7. The blue diamonds studied appear to group into two narrow, restricted populations (indicated by the arrows) within the range of color GIA GTL associates with the term blue. This is unlike the broader occurrence within the hue ranges of other colored diamonds, such as yellow, that we have encountered.

or Fancy Deep, and Fancy Vivid-the saturation range for blue diamonds is less than one third that in which yellow diamonds occur. This compressed saturation range means that the degree of difference in color appearance within each GIA GTL fancy grade is much narrower for blue diamonds than for yellow diamonds. For example, the range of appearances between Fancy Deep yellow and Fancy Vivid yellow is broader than the range between Fancy Deep blue and Fancy Vivid blue.

For the diamonds in our study, and in our general experience, we found that there are four smaller clusters in color space where blue diamonds most commonly occur. These are indicated on the grid in

Figure 8. The beige area on this grid illustrates the tone and saturation range observed for the blue diamonds in this study. Note that the tone values occur over a broader range than the saturation values. Within this area are four smaller clusters (here, shown as circles) in which the colors of blue diamonds are typically observed. figure 8 by the circles.

GIA GTL fancy grades represent a combined effect of tone and saturation (King et al., 1994). Figure 9 shows the general relationship of the

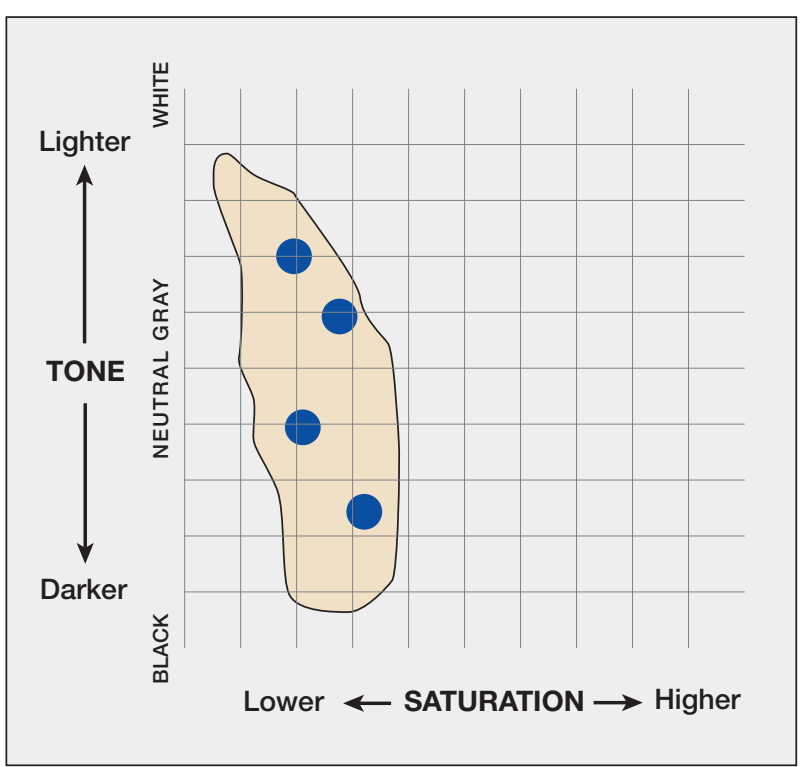




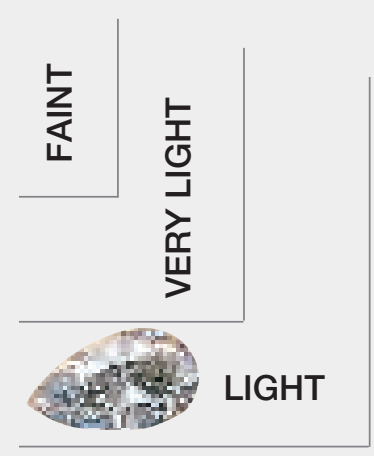

FANCY LIGHT
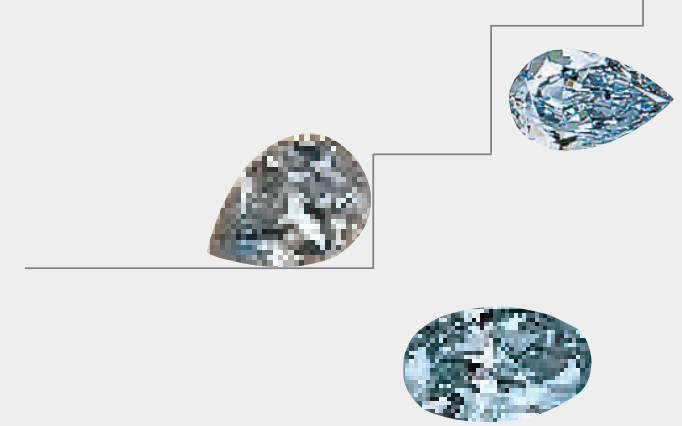

FANCY

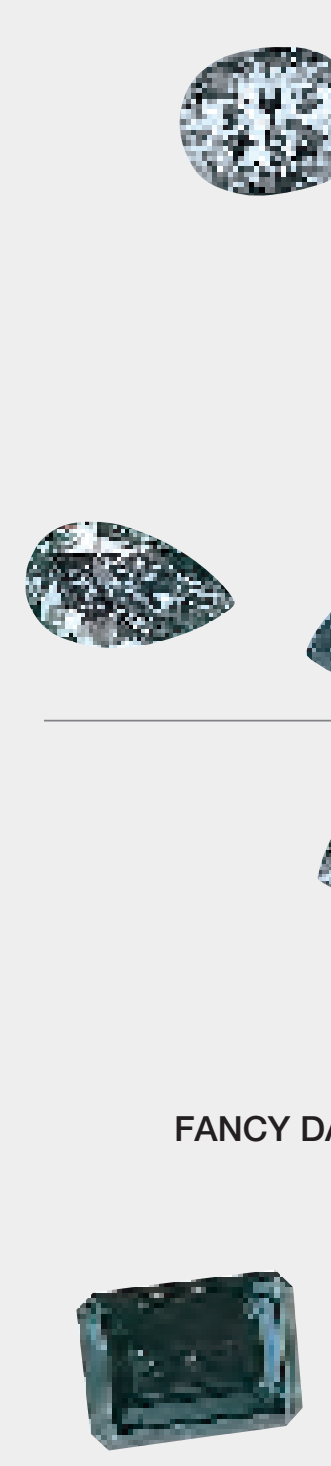

Figure 9. The images of blue diamonds superimposed on this chart of GIA GTL fancy grades illustrate the range of colors seen to date in blue diamonds. Note that the fancy-grade terms have a general relationship to the tone/saturation grid shown in figure 8. For example, the lighter, least saturated blue diamonds are in the upper left (Faint or Very Light), whereas the darker, most saturated blue diamonds fall toward the lower right (Fancy Deep to Fancy Vivid). For the purposes of this illustration, the sizes of some of the diamonds were altered relative to one another. It also should be noted that these images were compiled over several months. It may not be possible to find such a complete range of fancy grades in the market at a given time. Photos by Harold et Erica Van Pelt, Robert Weldon, Shane F. McClure, and Maha DeMaggio.

\section{FANCY VIVID}


images of several blue diamonds superimposed on a chart of the GIA GTL fancy-grade categories. Such a chart illustrates the subtle distinctions in color appearance between the various "fancy" terms.

Microscopic Examination. Clarity. As shown in figure 10, 29\% of the 294 diamonds analyzed for clarity were Flawless or Internally Flawless; 84\% were VS or higher (these data include diamonds in which clarity could potentially be improved even further by the removal of shallow imperfections). These percentages are much higher than we have observed in other diamonds. The high clarity grades of these polished blue diamonds are consistent with the high "purity" (i.e., clarity) of the rough as compared to most other diamonds (D. E. Bush, pers. comm., 1998).

Inclusions. In the subset of 62 diamonds that we examined specifically for inclusions, we found that approximately $35 \%(22)$ had no inclusions. Of the remaining stones, $78 \%$ had fractures or cleavages and only $25 \%$ had solid inclusions (and, in some cases, fractures or cleavages as well). In the small percentage of blue diamonds that contained solid inclusions, the tendency was for the inclusions to have a consistent shape and appearance. The inclusions in figure 11 are typical of those observed.

Figure 10. This pie chart illustrates how the 294 blue diamonds in this study that were clarity graded fit into the various GIA GTL clarity grade ranges. Although marketing factors may influence these results, the most surprising feature of this diagram is the very high percentage of diamonds in the Flawless/Internally Flawless category (much greater than for other diamonds).

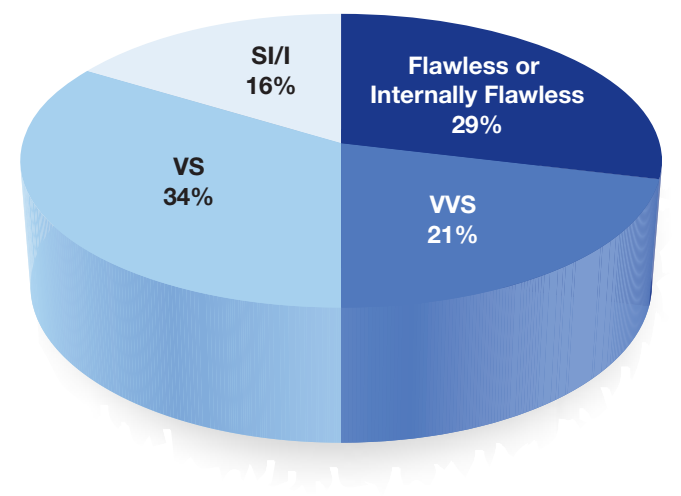

They tend to be opaque, dark, platy in habit, and would best be described as "flakes" with a slightly rough surface. They have an almost hexagonal, somewhat geometric outline. At magnification higher than 10x, the outlines are jagged and appear to be composed of interconnected and overlapping plates. When examined with reflected fiber-optic illumination, the inclusions appear gray and the roughness of the surface becomes most apparent.

With magnification and polarized light, the opaque inclusions are surrounded by visible strain halos composed of low-order interference colors. The inclusions do not align with any linear strain pattern of the host diamond. Instead, they seem to interfere with the otherwise orderly arrangement of the crystal structure, causing additional strain to the host crystal.

Since GIA acquired its Raman spectroscopy system in the fall of 1997, there has been limited opportunity to analyze the solid inclusions in blue diamonds. Raman analysis of solid inclusions in two diamonds proved inconclusive because of the small size of the inclusions and the fact that their rough surfaces caused the laser beam to scatter rather than return to the detector. The resulting Raman spectra were of poor quality and such weak intensity that they could not be matched with the spectral features of likely inclusion materials (such as graphite or a sulfide mineral inclusion; see following paragraph). EDXRF chemical analysis of the inclusions also was not diagnostic. For both techniques, the composition and size of the inclusion, its depth below the surface of the diamond, and its location within the diamond were all factors that prevented successful analysis.

From our visual observations of these inclusions with respect to their luster, dark color, morphology, and lack of transparency, we believe that the inclusions are either a sulfide or graphite (see, e.g., Harris, 1972; Meyer and Tsai, 1976). The fact that the inclusions are positioned in seemingly random directions, and they cut across distinct linear strain planes in the diamond, suggests that they are sulfides, because graphite forms most commonly along cleavage planes as a result of diamond alteration (see Harris, 1972; Harris and Vance, 1972; and Meyer and Tsai, 1976). Graphite inclusions would be expected to follow the planar structures in a diamond, rather than cutting across those layers. The excessive strain surrounding each of these inclusions also supports their identification as sulfides. Graphite forming as an alteration product along 

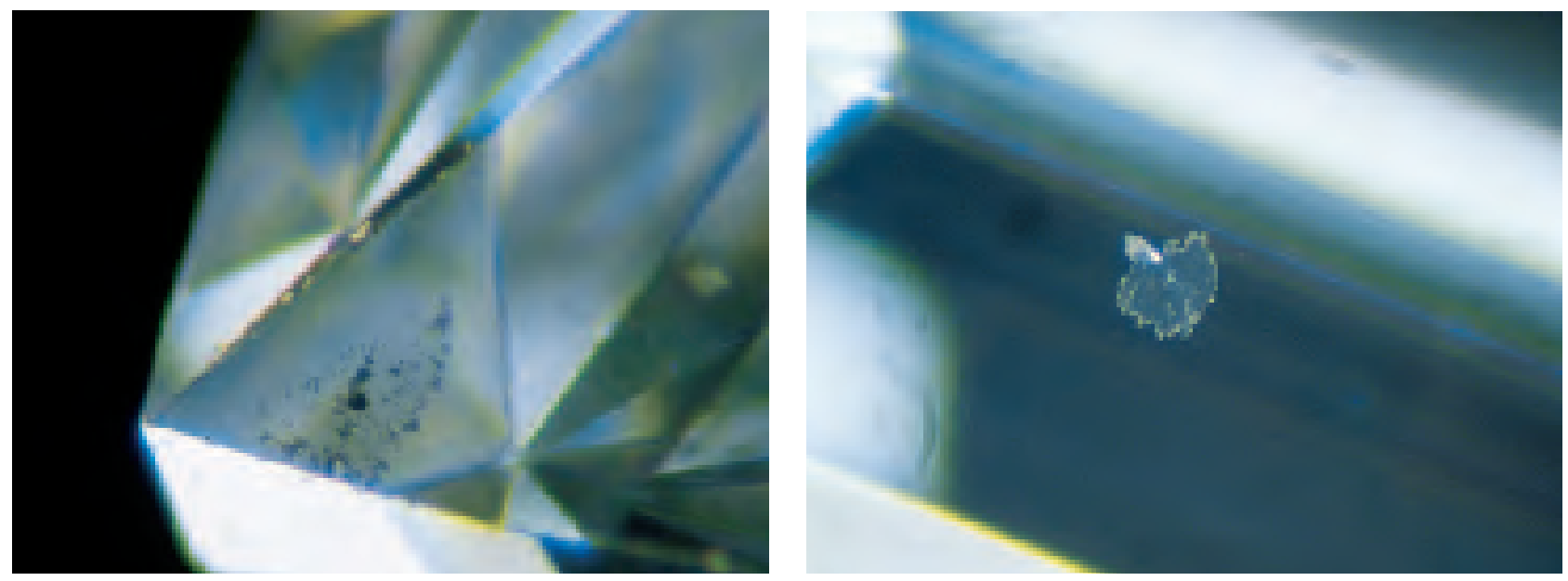

Figure 11. In 10 of the blue diamonds examined for inclusions in this study, we observed dark solid inclusions. On the left are several such inclusions in a $1.22 \mathrm{ct}$ Fancy blue diamond. On the right is an isolated example of a flattened inclusion in a $4.57 \mathrm{ct}$ Fancy Intense blue emerald cut. Visual examination suggests that these are probably sulfide mineral inclusions. Photomicrograph on the left is by Nick DelRe, magnified 30x; right, by Vincent Cracco, magnified 63x.

planes in the diamond would not be expected to produce detectable strain in the host, whereas visible strain halos around sulfide inclusions are typical (J. I. Koivula, pers. comm., 1998).

Graining. Internal graining is more common in blue diamonds than in near-colorless type Ia diamonds. Readily noticeable graining - which would carry a comment of "internal graining is present" on the report-was seen in approximately one-fourth of the 40 sample diamonds that had internal features. Graining is commonly believed to result from irreg-

Figure 12. This Fancy Deep blue diamond, which weighs more than $10 \mathrm{ct}$, exhibits parallel bands near the culet. Such graining is not uncommon in blue diamonds. When graining is this extensive, it affects the clarity grade. Photo by Vincent Cracco; magnified 10x.

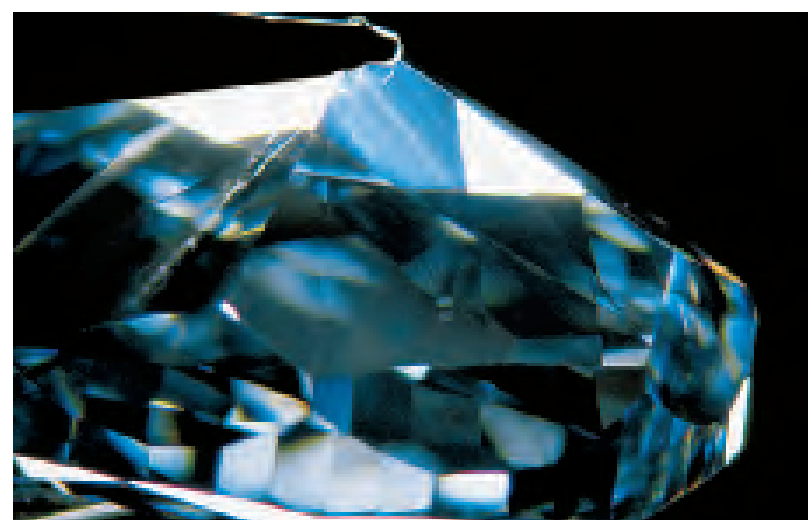

ularities in the crystal structure that form during or after crystallization. In our samples, the graining most often appeared as whitish bands (figure 12) or reflective internal planes.

Color Zoning. We saw color zoning, often very subtle, in more than 30 of the 62 diamonds in the inclusion subset. This zoning was most easily seen with diffused lighting and darkfield illumination. It typically appeared as discrete blue and colorless areas or parallel bands (figure 13). When cutting such a diamond, manufacturers try to locate the

Figure 13. Color zoning is often observed in blue diamonds. This photograph, taken at $10 \times$ magnification, shows parallel banding of colorless and blue areas. The position of the zones can have a significant impact on the face-up color (but typically not the clarity) of the diamond. Photo by Stephen Hofer, (c) GIA.

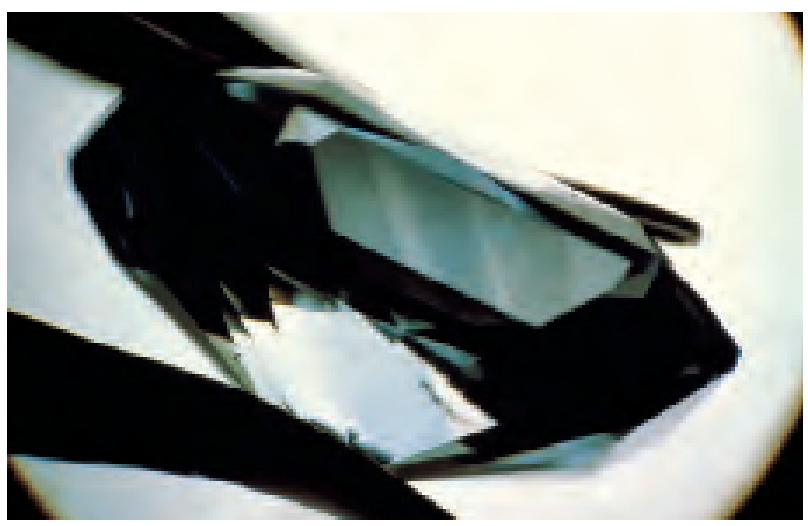




\section{Box B: MANUfaCtURING BLUE DiAMONDS}

Like many other aspects of blue diamonds, the manufacturing processes (planning, cutting, and polishing) often follow a path different from those used for nearcolorless diamonds and even other fancy colors. Several factors must be considered. First, the rough usually lacks a symmetrical form (figure B-1), unlike type Ia diamonds which often occur in common habits such as octahedra or dodecahedra. Thus, it may be more difficult than normal to determine appropriate cleaving and polishing directions. Second, the blue color may be unevenly distributed: Color zoning frequently occurs along growth directions or in isolated regions, often as alternating blue and near-colorless bands. Orienting these color zones to obtain the best face-up color appearance is a challenge similar to the cutting and polishing of blue sapphire, but the much higher value of blue diamonds (in which every point removed could mean a loss of thousands of dollars) means that the consequences are far more serious. Third, the surfaces of strongly asymmetric diamonds are commonly sculpted and translucent (Orlov, 1977). Thus, the cutter must polish several "windows" on the crystal to see any color zoning and inclusions before planning the cut.

These manufacturing challenges make modern computer-assisted cutting programs such as the Sarin Dia-Expert (Caspi, 1997) less useful in planning cuts for blue rough. Larger blue rough sometimes is shaped first in a rudimentary manner, maintaining flexibility regarding the final shape until the cutter can see the internal features more clearly. One may start out with plans for an oval or perhaps a pear shape, but make the final decision late in the faceting process. Weight recovery is often less than that typically obtained with colorless to near-colorless octahedral diamond rough.

The final face-up color of a blue diamond is much

Figure B-1. These rough blue diamonds (approximately 0.75 to $2.00 \mathrm{ct}$ ) are typical of the irregular shapes, color zoning, and sculpted, translucent surfaces associated with this material.

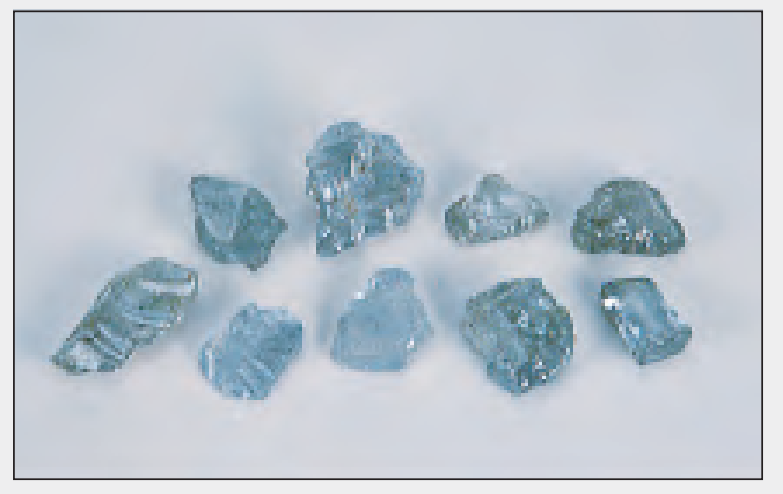

less predictable than most diamonds in the D-to- $\mathrm{Z}$ range or even than other fancy colors because of such features as color zoning. However, modern cutting and polishing techniques used to retain, improve, and spread color in all fancy-color diamonds also apply to blue diamonds. These techniques include the adaptation of "half-moon" facets and French culets to nearly all known brilliant-cut designs and shapes (figure B-2). Halfmoon-shaped facets are cut along the girdle on the pavilion (on straight or curved sides), usually at high angles relative to the girdle plane. These half-moon facets create more internal reflection, which produces a more intense face-up color appearance. A French culet distributes the color more evenly throughout. Conventional pavilion faceting typically concentrates the color in the points, corners, or heads of longer shapes such as ovals and pears. The color in the center (under the table) is weaker, creating an uneven two-tone effect. The French culet reduces this collection of color at the point and, with the half-moon facets, can prevent loss of color in the center of the faceted diamond.

Because of the irregular shape of the rough, the polishing directions are often difficult to orient. A cutter must be conscious of heat build-up and surface burning from misorientation on the polishing wheel, especially when working on large facets such as the table.

The fact that blue diamonds occupy a small region of color space means that subtle changes in appearance can influence the color description or grade. After deciding on a final shape, the cutter methodically adjusts the pavilion and crown angles, factoring in any previous experience with those angles in similarly colored rough. Often each side is cut to different angles, and the resulting effects on color appearance are compared. In fact, in some cases this asymmetrical faceting is left on the finished stone. Manufacturing blue diamonds is often a slow, arduous process that requires careful inspection of the face-up color appearance at each stage.

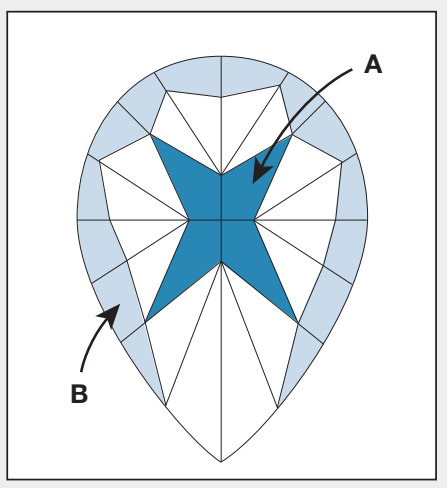

Figure B-2. The use of a French culet (A) and half-moon facets $(B)$ on the pavilion often creates a blue diamond with a stronger, more evenly colored face-up appearance. 


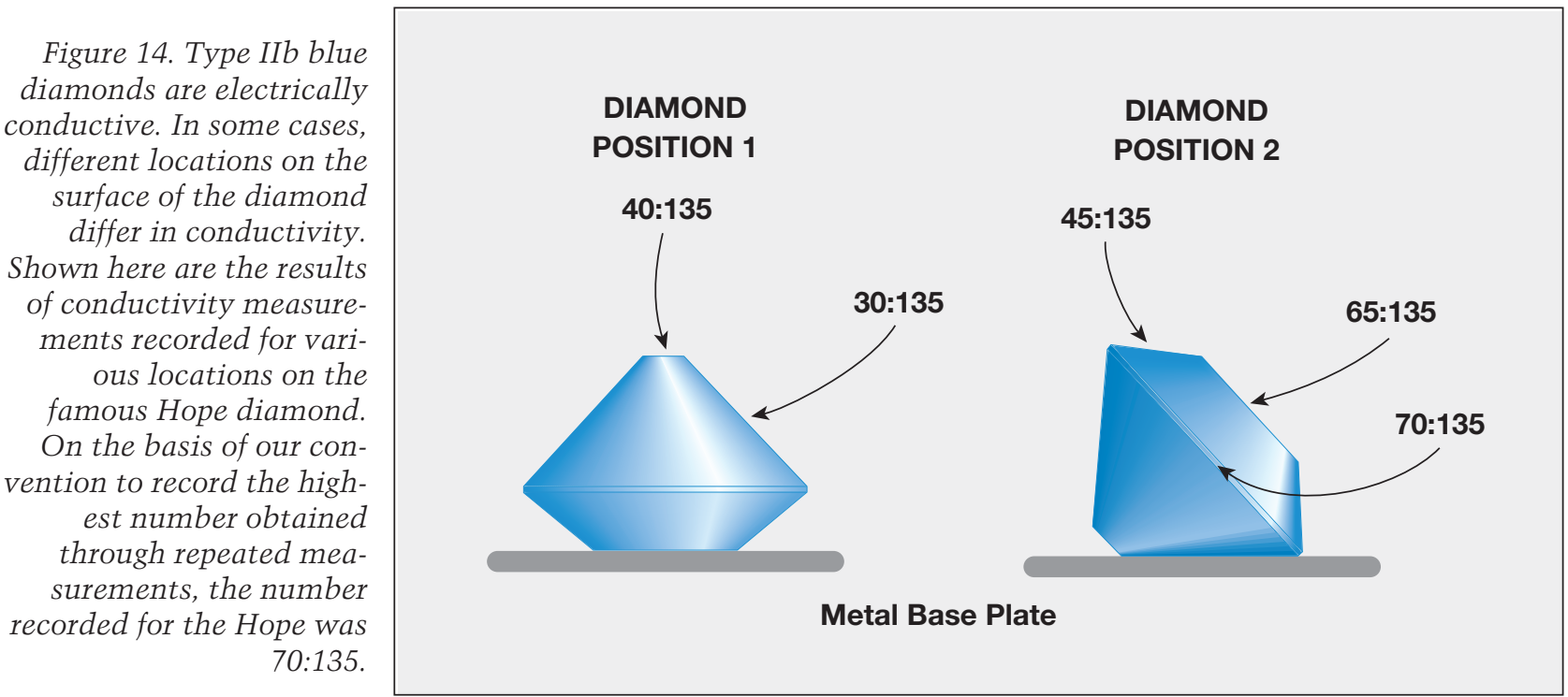

color zoning strategically to give the stone a uniform, more saturated blue appearance when it is viewed face-up (see Box B).

Fluorescence/Phosphorescence. Ninety-eight percent of the diamonds in this study showed no observable fluorescence to long-wave UV, and 91\% showed no observable fluorescence to short-wave UV. However, subtle fluorescence was difficult to observe because of the blue bodycolor combined with the purple surface reflections from the UV lamps. Of the small number of diamonds that did show a readily observable fluorescence to long- or short-wave UV radiation, the reaction was chalky blue to green or, rarely, red; the intensity was weak. It should be mentioned that extremely weak fluorescence in a diamond could be recorded as "none" on a GIA GTL report. Thus, the actual percentages of diamonds that fluoresce is likely to be higher than the values given above.

As is typical of type IIb blue diamonds, there was almost never a phosphorescence to long-wave UV, but a reaction to short-wave UV was common (again, see table 2). In fact, it was usually much easier to see phosphorescence from our samples than to see fluorescence. Of the blue diamonds that phosphoresced $(92 \%)$, the reaction varied from very weak to very strong, with almost three-quarters showing a very weak or weak reaction. The most common color was the same as the fluorescence color, chalky blue to green; rarely, it was red or orangy red. Because the important criterion in our typical gemological examinations of blue diamonds is whether or not a phosphorescent reaction is noted, for this study we recorded the duration of the phosphorescence in a random subset of 52 blue diamonds. The duration varied from a few seconds to as long as 45 seconds. Within the subset, we also noted that the Fancy Deep diamonds had the most persistent phosphorescence, at an average of $18 \mathrm{sec}-$ onds. During our most recent examination of the (Fancy Deep) Hope diamond, we checked this feature closely and noted that the total phosphorescence, which was red, actually lasted almost 45 seconds.

Electrical Conductivity. All the diamonds in our study were electrically conductive. The samples showed a wide range of measured values, both in general and within each fancy-grade category (see table 2). The lowest value measured among our samples was 10:135, and the highest was 120:135 (again, reading on the diamond and reading on the metal plate).

As mentioned above, we sometimes noted a variation in conductivity within individual stones by touching the probe to different areas. A good example is the data we recorded for the Hope diamond in 1996, as shown in figure 14.

Visible Absorption Spectrum. Type IIb blue diamonds lack sharp absorption bands in their visible spectra. Rather, they exhibit a gradually increasing absorption toward the red end of the spectrum. Figure 15 shows the absorption spectra of four blue diamonds of differing intensities and a gray diamond. 
Infrared Absorption Spectrum. Figure 16 shows the mid-infrared spectra of the same five diamonds for which the visible spectra were illustrated in figure 15. The features that are characteristic of a type IIb diamond were more intense in the two diamonds with a stronger blue color relative to the other diamonds.

\section{DISCUSSION}

Type $\mathrm{Ilb}$ blue diamonds are unique in a number of their gemological properties, such as their electrical conductivity together with their phosphorescence to short-wave UV. This allows for their separation from other materials more readily than is the case for many gems. In addition, diamonds of other types that are described as blue typically are not of the same hue, nor do they have similar reactions to other gemological tests. Therefore, this study focused less on the identification of natural from treated or synthetic blue diamonds and more on understanding their distinctive color appearance. Because of the critical role that color plays in the evaluation of type $\mathrm{IIb}$ blue diamonds, the following discussion will examine the relationship of the various color appearances to the characteristics documented in natural type IIb blue diamonds.

Color Relationships Among Blue Diamonds. An important goal of this study was to better understand how blue diamonds relate to one another in color space-that is, hue, tone, and saturationespecially as these relationships are articulated in the GIA GTL color grading system for colored diamonds.

Hue. From the tight hue clustering found in the type $\mathrm{IIb}$ blue diamonds studied, it appears that boron, the element that causes the color (again, see Box A), creates a very limited range of color appearance.

Tone and Saturation. For many people, tone and saturation are the most difficult aspects to discriminate in the face-up color appearance of a faceted gemstone. Because the hue range is limited, the variation in color appearance among blue diamonds is mainly determined by the tone and saturation of their colors. In the GIA GTL grading system, a variety of color appearances can be included within the same fancy grade. The system uses the same set of fancy grades for describing all colored diamonds, but for blue diamonds, these grades are compressed into a smaller region of color space.

As the results of this study indicate, the colors of type IIb blue diamonds occur in a relatively wide tone range (i.e., light to dark) but a narrower saturation range (i.e., weak to strong intensity) in color space (see again figure 8). Because of this distribution, the color appearances that one usually sees in blue diamonds are more likely to result from differences in tone (see figure 17). For an unfamiliar

Figure 15. The visible spectra of blue diamonds lack sharp absorption bands; rather, they have gradually increasing absorption toward the red end of the spectrum. Spectra $A$ to $D$ are for blue diamonds of differing color intensity ( $A=$ Fancy Intense, $B=$ Fancy, $C=$ Fancy Light, and $D=$ Very Light); spectrum $E$ is for a Fancy Light gray diamond. These spectra were recorded at low (liquid nitrogen) temperature. The diamonds, all oval or marquise shapes of similar weights and proportions, were positioned so that light entered a bezel facet and exited an opposite pavilion facet. Each of these spectra was normalized to the approximate sample path length, so the spectra could be compared. Because of the similarity of the spectra from one sample to the next, we could not correlate them with the depth of color in the five diamonds. However, this similarity in spectra is consistent with the narrow range of color appearances in which blue diamonds occur.

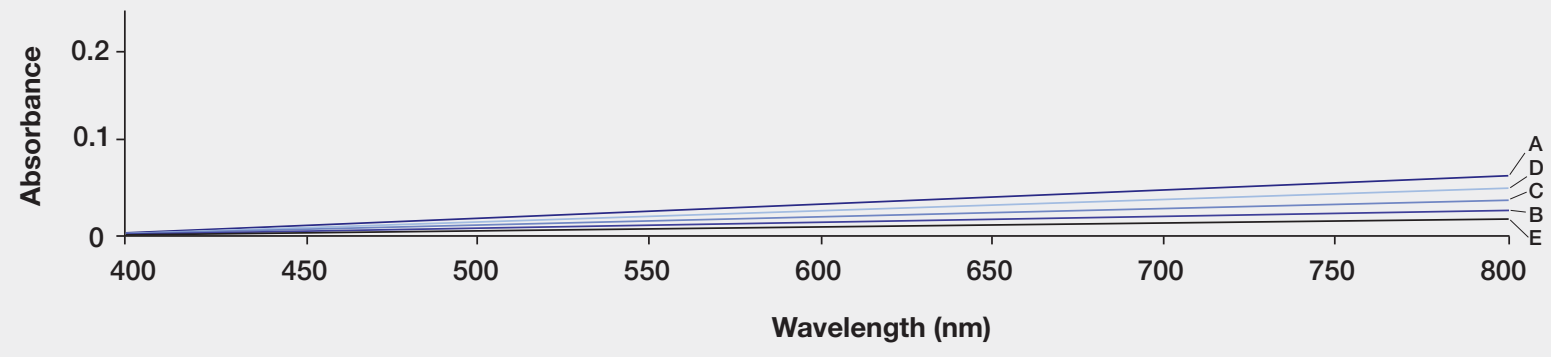


observer of blue diamonds, differences in tone can be misinterpreted as saturation differences.

As mentioned earlier, the colors of most blue diamonds tend to be concentrated around four clusters on the tone/saturation grid (see again figure 8). This clustering can cause misconceptions about the color grades of blue diamonds. For example:

1. Some of these clusters fall across grade boundaries. In this situation, subtle differences in color appearance between two blue diamonds can result in their being described with different fancy grades (figure 18). Judging from the more common situation involving yellow diamonds, some people may expect the differences in color appearance for some blue diamonds with different grades to be more pronounced than is actually the case.

2. When one looks at two blue diamonds that fall within the same cluster on the tone/saturation grid, at first these two colors may look sufficiently different that the observer feels that two grades are warranted. However, when the colors of these two blue diamonds are compared to that of a third diamond that is noticeably different in appearance, the close correspondence in color of the first two becomes apparent (figure 19). In this situation, use of two grades to describe the colors of blue diamonds that occur within the same cluster is not warranted.

3. In contrast to the colors of blue diamonds that fall within a cluster, a situation can occur where the color of a less-commonly seen blue diamond falls outside one of the four clusters. Despite the differences in appearance, these blue diamonds could still be assigned the same grade.

It is also important to recognize that the narrow saturation range in which blue diamonds occur is relatively close to the neutral gray region of color space. In general, the eye can discern fewer color distinctions in this region. Again, though, the trade expects-and an orderly description system implies-an equal number of grades for blue diamonds as for other colors despite the inequality between respective areas of color space. For a blue diamond and a yellow diamond in the same grade, the color of the yellow diamond is relatively stronger so the color differences between grades are more readily perceived.

Consequently, our experience with blue diamonds suggests the following:

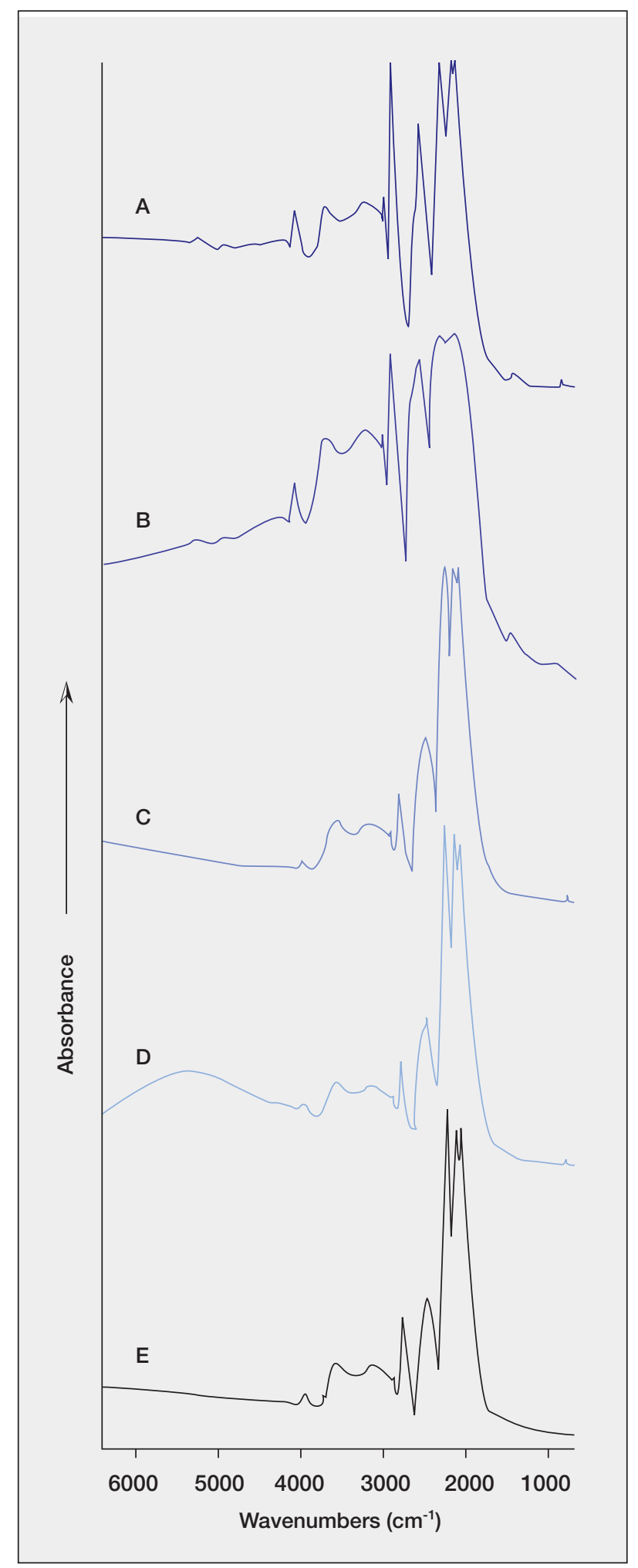

Figure 16. The mid-infrared spectra of the five diamonds for which visible spectra are presented in figure 15 reveal the pattern of absorption features that is characteristic of type IIb diamonds. These features are most intense for the two stronger-blue diamonds (spectra $A$ and $B$ ). 


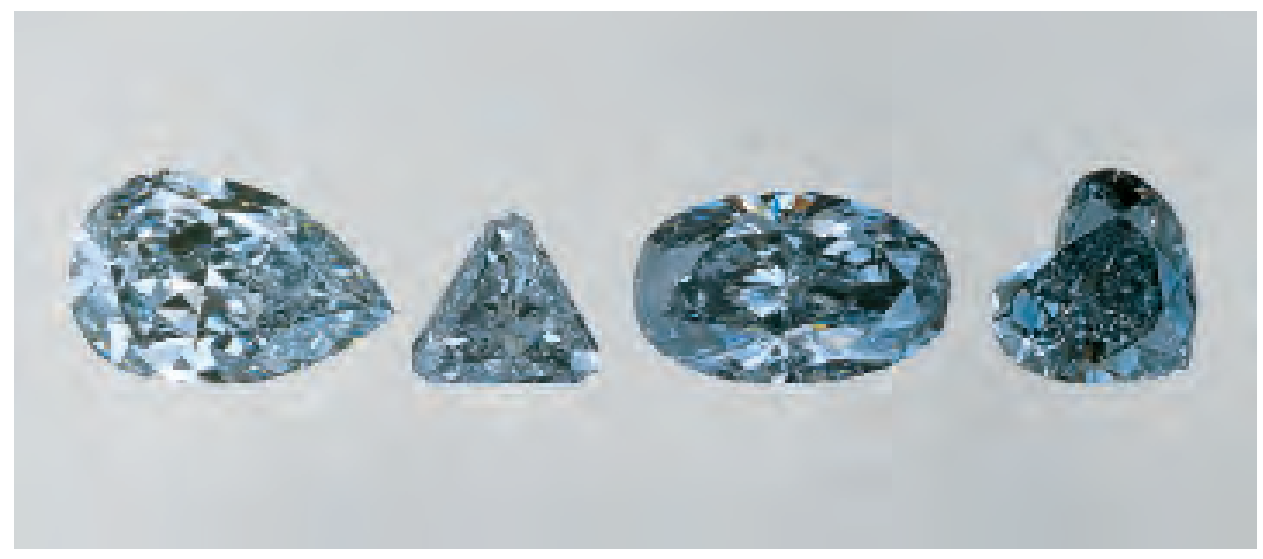

Figure 17. These four Fancy blue diamonds (from left to right, 2.03, $0.48,2.01$, and $1.15 \mathrm{ct}$ ) are similar in saturation, but they differ in tone, that is, they become progressively darker from left to right. These differences might be misinterpreted as increasing saturation by an inexperienced observer. Photo (C) Harold et Erica Van Pelt.

1. Color grading of blue diamonds requires use of a controlled methodology and grading environment to ensure the maximum consistency and repeatability.

2. To evaluate the significance of a difference between two colors, it is important to have references of known color location in color space for bracketing (see figure 20).

Clarity. The fact that blue diamonds are generally of high clarity is related to their type, not their color. Other type II diamonds, such as colorless type IIa diamonds, as well as some pink diamonds from India (Scarratt, 1987), show the same high clarity.

Figure 19. Because of the clustering in tone and saturation encountered with blue diamonds, those in sim-

ilar clusters (such as the two diamonds on the left,

1.19 and $2.03 \mathrm{ct}$ ) may initially appear to differ in depth of color more than they actually do, since the observer has a natural tendency to make distinctions. When a diamond of different tone and saturation (far right, $1.82 \mathrm{ct}$ ) is placed next to them, the similarities between the first two become clearer. Unlike the situation in figure 18, these first two diamonds were not near a grade boundary, so both were graded Fancy blue. Photo (c) Harold et Erica Van Pelt.
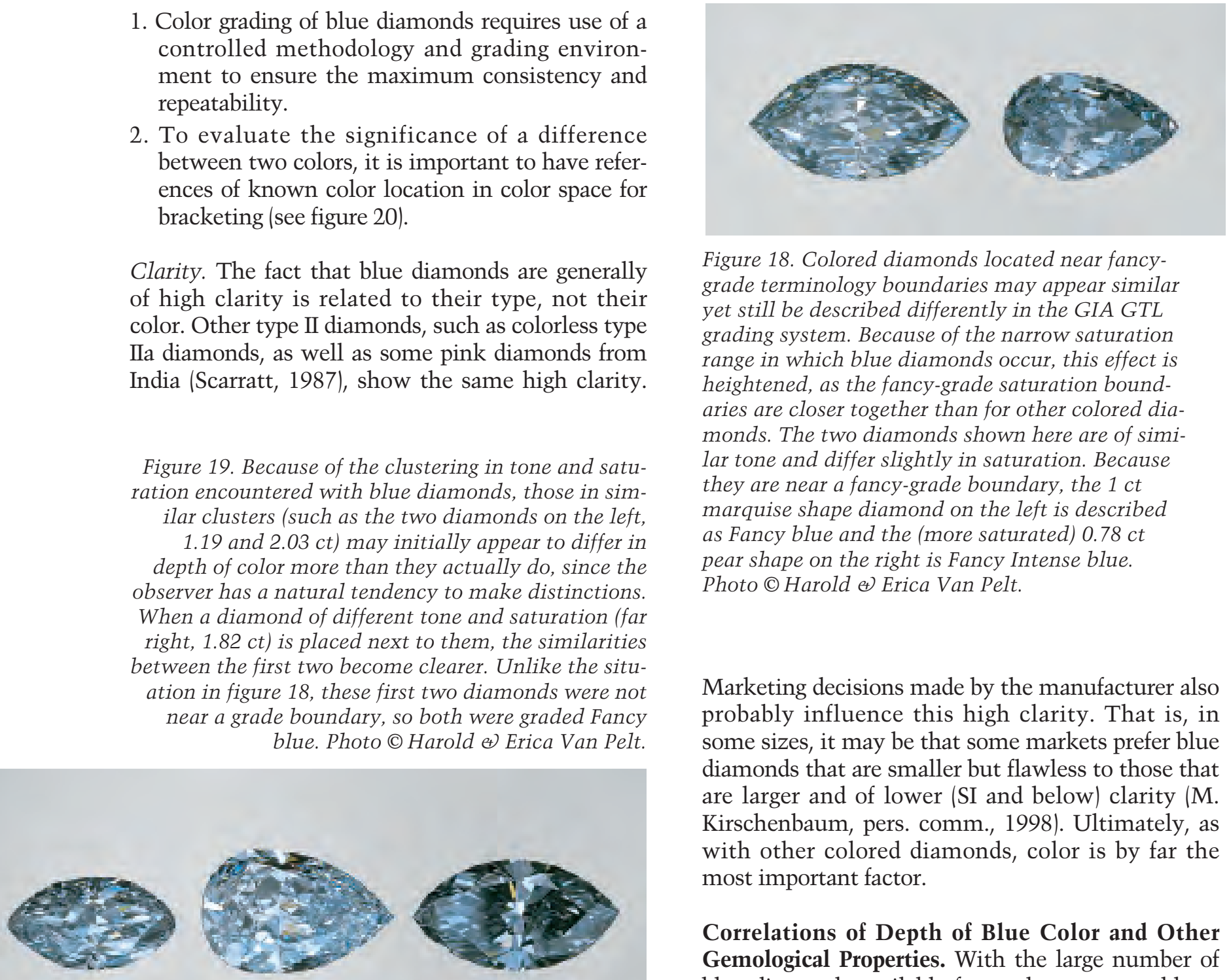

Figure 18. Colored diamonds located near fancygrade terminology boundaries may appear similar yet still be described differently in the GIA GTL grading system. Because of the narrow saturation range in which blue diamonds occur, this effect is heightened, as the fancy-grade saturation boundaries are closer together than for other colored diamonds. The two diamonds shown here are of similar tone and differ slightly in saturation. Because they are near a fancy-grade boundary, the $1 \mathrm{ct}$ marquise shape diamond on the left is described as Fancy blue and the (more saturated) $0.78 \mathrm{ct}$ pear shape on the right is Fancy Intense blue. Photo (c) Harold et Erica Van Pelt.

Marketing decisions made by the manufacturer also probably influence this high clarity. That is, in some sizes, it may be that some markets prefer blue diamonds that are smaller but flawless to those that are larger and of lower (SI and below) clarity (M. Kirschenbaum, pers. comm., 1998). Ultimately, as with other colored diamonds, color is by far the most important factor.

Correlations of Depth of Blue Color and Other Gemological Properties. With the large number of blue diamonds available for study, we were able to establish some general correlations between depth of color and other properties (again, see table 2). 
Figure 20. For centuries, people have devised ways to understand color appearance relationships through various order systems such as those shown in the background of this photograph.

Understanding the color ordering of gems is particularly important for grad-

ing blue diamonds. The bracelet contains a $3.56 \mathrm{ct}$ Fancy Dark gray-blue oval brilliant with 30.87 carats of D-color, internally flawless pear brilliants. In the three rings are a $2.87 \mathrm{ct}$

Fancy Deep blue emerald cut, a 1.64 ct Fancy grayblue marquise, and $a$

12.38 ct Fancy blue rectangular modified brilliant. The three unmounted pear brilliants are a $1.02 \mathrm{ct}$ Fancy blue, a $4.02 \mathrm{ct}$ Fancy Intense blue, and $a$ 15.29 ct Fancy blue.

Courtesy American Siba Corp. and Rima Investors Corp. Photo by Robert Weldon.

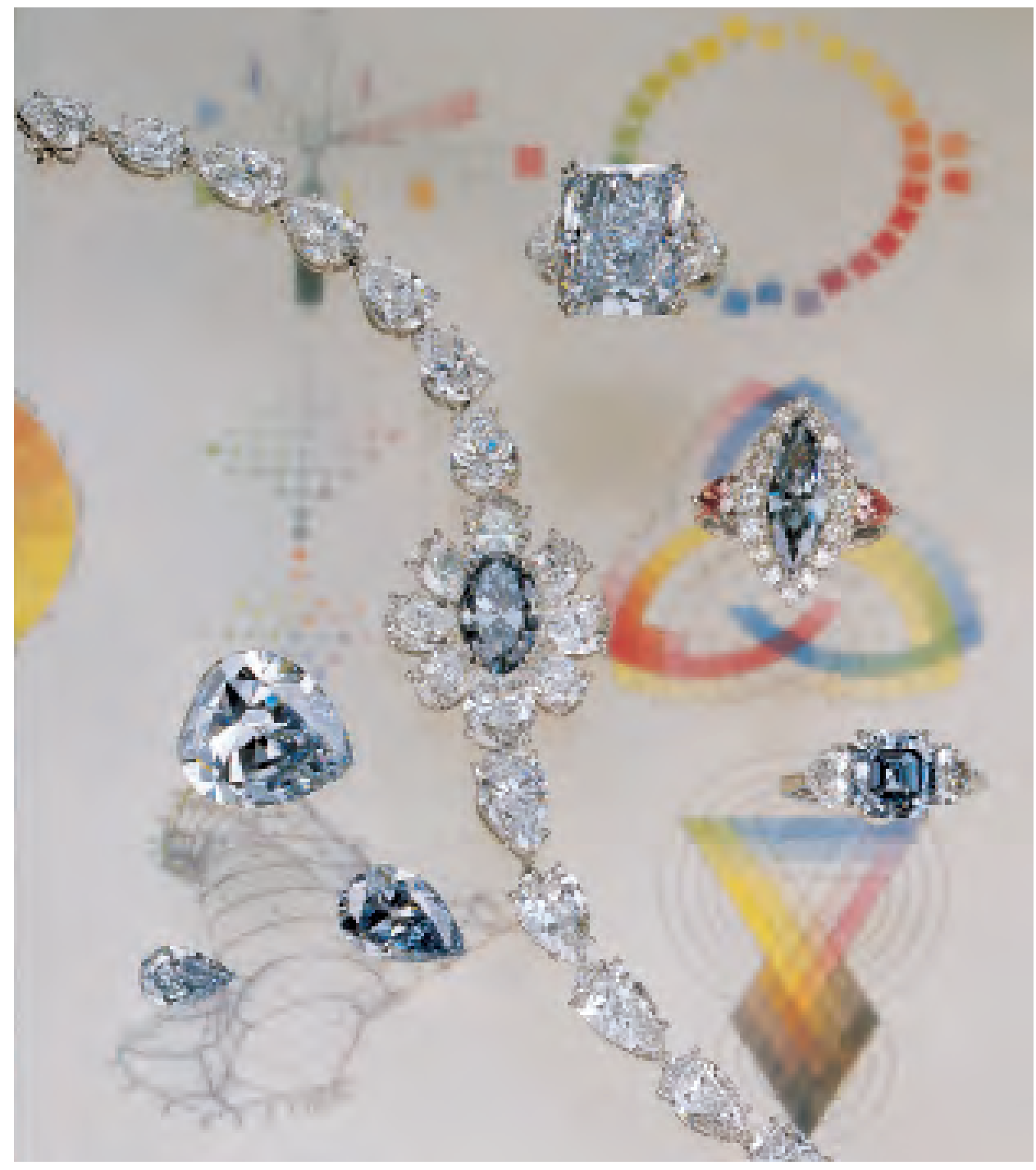

Phosphorescence. In general, the Fancy Deep blue diamonds had the longest lasting phosphorescence. There was no clear correlation between intensity of phosphorescence and strength of color (more than $50 \%$ across all grades showed weak phosphorescence).

Electrical Conductivity. While it is difficult to establish a direct relationship (partly due to the problems encountered in obtaining consistent measurements, as mentioned above), the general trend among our samples was for the blue color to be darker and/or stronger as the electrical conductivity increased. There are exceptions to this behavior, as can be seen by the measurements recorded for individual diamonds within a grade range (see table 2). Also, we have noted several highly conductive dark gray (i.e., unsaturated) diamonds, and we recently encountered a Fancy Light blue diamond with a conductivity value that was similar to those of many of the blue diamonds graded as Fancy Deep or Fancy Dark.

Although electrical conductivity is not a completely accurate indicator, diamond manufacturers occasionally use strength of conductivity to identify potentially stronger and weaker areas of color in the rough diamond (K. Ayvazian, pers. comm., 1998). They believe that in combination with visual observations of color zoning, this can be helpful in producing the most saturated face-up color appearance possible in the finished diamond (again, see Box B).

Visible and Infrared Spectra. Comparison of the five spectra in figure 15 shows very little difference in absorption. We could not completely correlate the intensity of the face-up color of these five dia- 
TABLE 3. Blue diamond identification.

\begin{tabular}{|c|c|c|c|c|}
\hline Property & Natural diamonda & Natural diamonda & Treated diamond ${ }^{b}$ & Synthetic diamond ${ }^{c}$ \\
\hline Type & Ilb & lla or la & lla or la & $\mathrm{llb}$ \\
\hline Color & $\begin{array}{l}\text { Pale to deeply } \\
\text { colored blue }\end{array}$ & $\begin{array}{l}\text { Pale to deeply colored } \\
\text { green-blue and, rarely, } \\
\text { blue to violet }\end{array}$ & $\begin{array}{l}\text { Pale to deeply colored } \\
\text { green-blue and, rarely, } \\
\text { blue }\end{array}$ & $\begin{array}{l}\text { Pale to deeply } \\
\text { colored blue }\end{array}$ \\
\hline Cause of color & Trace amounts of boron & Radiation exposure & Radiation exposure & Trace amounts of boron \\
\hline Size of cut stones & To more than $50 \mathrm{ct}$ & Up to $20 \mathrm{ct}$ & $\begin{array}{l}\text { Depends on sample } \\
\text { selected for treatment }\end{array}$ & Less than $1 \mathrm{ct}$ \\
\hline \multicolumn{5}{|l|}{$\begin{array}{l}\text { Features seen } \\
\text { with magnification }\end{array}$} \\
\hline $\begin{array}{l}\text { Color } \\
\text { distribution }\end{array}$ & $\begin{array}{l}\text { Often even, sometimes } \\
\text { uneven with blue/ } \\
\text { colorless zoning }\end{array}$ & $\begin{array}{l}\text { Even, sometimes uneven } \\
\text { with blue and near- } \\
\text { colorless zones; color } \\
\text { zoning may be located } \\
\text { near surface radiation } \\
\text { stains }\end{array}$ & $\begin{array}{l}\text { Even, sometimes uneven } \\
\text { with blue and near-color- } \\
\text { less zones; color zoning may } \\
\text { follow faceted shape- } \\
\text { often concentrated at } \\
\text { the culet }\end{array}$ & $\begin{array}{l}\text { Usually uneven, with } \\
\text { blue and near-colorless } \\
\text { zones related to internal } \\
\text { growth sectors; may form } \\
\text { cross-shaped pattern }\end{array}$ \\
\hline Graining & $\begin{array}{l}\text { Sometimes whitish } \\
\text { reflective or transparent } \\
\text { graining }\end{array}$ & $\begin{array}{l}\text { Occasional planar } \\
\text { graining, sometimes } \\
\text { colored or, rarely, } \\
\text { whitish }\end{array}$ & Not diagnostic & $\begin{array}{l}\text { Planar graining marking } \\
\text { boundaries of color zoning, } \\
\text { may form cross- or hourglass- } \\
\text { shaped patterns }\end{array}$ \\
\hline Inclusions & $\begin{array}{l}\text { Usually free of mineral } \\
\text { inclusions; sometimes } \\
\text { opaque black } \\
\text { inclusions }\end{array}$ & $\begin{array}{l}\text { Sometimes mineral } \\
\text { inclusions }\end{array}$ & $\begin{array}{l}\text { Sometimes mineral } \\
\text { inclusions }\end{array}$ & $\begin{array}{l}\text { Elongated or rounded } \\
\text { opaque metal inclusions, } \\
\text { isolated or in small } \\
\text { groups; occasional } \\
\text { pinpoints }\end{array}$ \\
\hline $\begin{array}{l}\text { Other internal } \\
\text { features }\end{array}$ & $\begin{array}{l}\text { Occasional fractures } \\
\text { or cleavages }\end{array}$ & $\begin{array}{l}\text { Occasional fractures, } \\
\text { cleavages, pinpoints, } \\
\text { clouds }\end{array}$ & $\begin{array}{l}\text { Occasional fractures, } \\
\text { cleavages, pinpoints, } \\
\text { clouds }\end{array}$ & $\begin{array}{l}\text { Generally free of fractures } \\
\text { and cleavages }\end{array}$ \\
\hline Strain & $\begin{array}{l}\text { Weak to strong } \\
\text { anomalous double } \\
\text { refraction, sometimes } \\
\text { in parallel or cross- } \\
\text { hatched patterns }\end{array}$ & $\begin{array}{l}\text { Weak to strong } \\
\text { anomalous double } \\
\text { refraction, sometimes } \\
\text { in parallel or cross- } \\
\text { hatched patterns }\end{array}$ & $\begin{array}{l}\text { Weak to strong } \\
\text { anomalous double } \\
\text { refraction, sometimes } \\
\text { in parallel or cross- } \\
\text { hatched patterns }\end{array}$ & $\begin{array}{l}\text { Weak anomalous } \\
\text { double refraction, } \\
\text { sometimes in a cross } \\
\text { pattern }\end{array}$ \\
\hline $\begin{array}{l}\text { Visible } \\
\text { absorption } \\
\text { spectra }\end{array}$ & $\begin{array}{l}\text { No sharp bands, } \\
\text { increasing absorption } \\
\text { toward the red end } \\
\text { of the spectrum }\end{array}$ & $\begin{array}{l}\text { Sometimes weak to } \\
\text { strong bands ( } 415 \text {, } \\
478,496,504, \\
595 \mathrm{~nm})\end{array}$ & $\begin{array}{l}\text { Sometimes weak to } \\
\text { strong bands }(415, \\
478,496,504, \\
595 \mathrm{~nm})\end{array}$ & $\begin{array}{l}\text { No sharp bands, } \\
\text { increasing absorption } \\
\text { toward the red end of } \\
\text { the spectrum }\end{array}$ \\
\hline $\begin{array}{l}\text { Ultraviolet } \\
\text { luminescence }\end{array}$ & $\begin{array}{l}\text { Usually none, rarely } \\
\text { weak red to orange-red, } \\
\text { occasionally blue to } \\
\text { greenish blue to SWUV }\end{array}$ & $\begin{array}{l}\text { Sometimes weak to } \\
\text { strong blue, greenish } \\
\text { blue, green, yellow, } \\
\text { or orange }\end{array}$ & $\begin{array}{l}\text { Sometimes weak to } \\
\text { strong blue, greenish } \\
\text { blue, or green }\end{array}$ & $\begin{array}{l}\text { Weak to moderate blue to } \\
\text { greenish blue to SWUV; } \\
\text { uneven distribution related } \\
\text { to internal growth sectors }\end{array}$ \\
\hline $\begin{array}{l}\text { Phosphor- } \\
\text { escence }\end{array}$ & $\begin{array}{l}\text { Blue to green, rarely } \\
\text { red to orangy red }\end{array}$ & None & None & $\begin{array}{l}\text { Moderate to strong blue, } \\
\text { sometimes with orange; } \\
\text { persistent duration }\end{array}$ \\
\hline $\begin{array}{l}\text { Cathodo- } \\
\text { luminescence }\end{array}$ & $\begin{array}{l}\text { Usually greenish blue, } \\
\text { sometimes shows } \\
\text { cross-hatched pattern }\end{array}$ & Not examined & Not examined & $\begin{array}{l}\text { Weak to strong greenish } \\
\text { blue; sometimes with un- } \\
\text { even distribution related to } \\
\text { internal growth sectors; some } \\
\text { sectors show no reaction }\end{array}$ \\
\hline Other features & Electrically conductive & $\begin{array}{l}\text { Green or brown radiation } \\
\text { stains on surface or } \\
\text { along open fractures }\end{array}$ & $\begin{array}{l}\text { May exhibit residual } \\
\text { radioactivity }\end{array}$ & $\begin{array}{l}\text { Electrically conductive, } \\
\text { may be attracted by a } \\
\text { strong magnet }\end{array}$ \\
\hline
\end{tabular}

a Adapted from Shigley et al. (1995) and (for natural type Ilb blue diamonds) based on data gathered for this study.

${ }^{b}$ Based on data accumulated at the GIA Gem Trade Laboratory and GIA Research.

- Based on observations by GIA Research and the DTC Research Centre.

monds (as expressed by the fancy grade description) and their spectra. This lack of correlation can be attributed to several factors. First, these spectra were recorded for a light path through the bezel and pavilion facets of the stone in an attempt to measure the bodycolor. The color grade, however, was established by visual observation of the face-up color. Second, the face-up color appearance of a col- 
ored diamond is determined not just by the bodycolor but also by effects of the faceting style and the lighting and observation conditions. Nonetheless, the overall similarity of these five spectra lends support to the results of the visual observation portion of this study, that the range of color appearances from gray to gray-blue to blue is limited.

Although the infrared spectra of all 5 stones were similar, we did note that the type IIIb features were most prominent in the two diamonds with the strongest blue color.

Identification and Separation. The properties and appearance of type $\mathrm{Ib}$ blue diamonds do not typically overlap with those of treated blues, and synthetic type $\mathrm{Ib}$ blue diamonds are not available on the commercial market. Still, it is valuable to understand the separation of these diamonds. Table 3 presents a brief comparison of the gemological properties of natural, treated, and synthetic blue diamonds.

\section{SUMMARY AND CONCLUSION}

The special qualities of blue diamonds, and the rich history associated with many of them, has made such diamonds highly valued and desirable in the gem and jewelry industry today. The earliest references to blue diamonds came centuries ago, when the Tavernier Blue was brought from India. Although blue diamonds have occasionally been reported from sources other than the Premier mine in South Africa, this historic mine has produced most of the blue diamonds seen in the marketplace. Currently an underground operation, the Premier mine is viable primarily because of the handful of blue or large colorless "specials" that are recovered each year.

Because virtually all the diamonds described as blue by the GIA Gem Trade Laboratory are type IIb, we chose to focus on this type for our study. In addition to their unique color attributes, type IIb diamonds have distinctive traits such as electrical conductivity, boron as the coloring agent, and a characteristic phosphorescent reaction to short-wave UV. Fancy Deep blue diamonds had the longest phosphorescence, but there was no correlation to intensity of the phosphorescence. Also, there was a trend among the samples for diamonds that were a stronger and/or darker blue to have higher electrical conductivity. We have found that blue diamonds typically are of higher clarity than other diamonds. However, the fact that the rough may be color zoned and is typically irregular in shape makes the manufacturing of these diamonds challenging.

A key goal of this study was to provide a better understanding of the narrow color range in which type IIb blue diamonds occur and the color appearances associated with their various GIA GTL fancy grades. Blue diamonds are unique among colored diamonds in that they occupy isolated regions in their hue range and primarily occur in four small tone/saturation clusters. If we understand this, we can understand how these diamonds relate to one another and to diamonds of other colors.

Acknowledgments: At the GIA Gem Trade Laboratory (GIA GTL), Thomas Gelb, Scott Guhin, and Joshua Cohn assisted with visual color observations and analysis. Mark Van Daele and Kim Cino performed database analyses, and Elizabeth Doyle, Giulia Goracci, Sam Muhlmeister, and Shane Elen assisted in the data collection. John Koivula performed inclusion analysis and commentary. Dr. Emmanuel Fritsch, of the University of Nantes, France, offered comments on the text. Basil Watermeyer, of Steinmetz-Ascot, Johannesburg, South Africa, provided information on manufacturing blue diamonds. Dr. Jeffrey E. Post, curator of gems and minerals at the Smithsonian Institution, Washington, DC, supplied information on the Hope diamond. Sam Abram of American Siba Corp., Ara Arslanian of Cora Diamond Corp., Martin Kirschenbaum of M. Kirschenbaum Trading, Ali Khazaneh of Rima Investors Corp., and Isaac Wolf loaned diamonds for this study and offered valuable comments. Special thanks for helpful discussions to Gareth Penny, diamond consultant, and David E. Bush, senior divisional diamond revenue manager, De Beers Corporate Headquarters, Johannesburg; and Angus Galloway, general manager, and Mike Semple, market controller, Harry Oppenheimer House, Kimberley, South Africa. Hans Gastrow, general manager of the Premier mine, South Africa, provided a tour of the mine and production information.

\section{REFERENCES}

Austin I.G., Wolfe R. (1956) Electrical and optical properties of a semiconducting diamond. Proceedings of the Physical Society of London B, Vol. 69, pp. 329-338.

Balfour I. (1997) Famous Diamonds. Christie, Manson and Woods Ltd., London.

Benson L. (1959) Highlights at the Gem Trade Lab in Los Angeles-Electrical conductivity in blue diamonds. Gems $\nrightarrow$ Gemology, Vol. 9, No. 10, pp. 296-298. 
Blackwell D.E., Sutherland G.B.B.M. (1949) The vibrational spectrum of diamond. Journal de Chimie, Vol. 46, pp. 9-15.

Brophy J.J. (1955) Preliminary study of the electrical properties of a semiconducting diamond. Physical Review, Vol. 99, pp. 1336-1337.

Bruton E. (1978) Diamonds, 2nd ed. Chilton Book Co., Radnor, PA

Caspi A. (1997) Modern diamond cutting and polishing. Gems Gemology, Vol. 33, No. 2, pp. 102-121

Cassedanne J.P. (1989) Diamonds in Brazil. Mineralogical Record, Vol. 20, No. 5, pp. 325-336.

Chrenko R.M. (1973) Boron, the dominant acceptor in semiconducting diamond. Physical Review B, Vol. 7, No. 10, pp. 4560-4567.

Christie's Jewellery Review 1995 (1996) Christie's International Jewellery Dept., Geneva and New York.

Collins A.T., Williams A.W.S. (1971) The nature of the acceptor centre in semiconducting diamond. Journal of Physics C: Solid State Physics, Vol. 4, pp. 1789-1800.

Crowningshield G.R. (1959) Highlights at the Gem Trade LabElectrical conductivity meter. Gems «) Gemology, Vol. 9, No. 10, p. 291.

Crowningshield G.R. (1971) General Electric's cuttable synthetic diamonds. Gems ef Gemology, Vol. 13, No. 10, pp. 302-314.

Custers J.F.H. (1952) Unusual phosphorescence of a diamond. Physica, Vol. 18, No. 8-9, pp. 489-496.

Custers J.F.H. (1954) Letter to the editor-Type II-b diamonds. Physica, Vol. 20, pp. 183-184.

Custers J.F.H. (1955) Semiconductivity of a type II-b diamond. Nature, Vol. 176, No. 4473, pp. 173-174.

Custers J.F.H., Dyer H.B. (1954) Discrimination between natural blue diamonds and diamonds coloured blue artificially. Gems (4) Gemology, Vol. 7, No. 2, pp. 35-37.

Custers J.F.H., Dyer H.B., Raal F. (1960) A simple method of differentiating between natural blue diamonds and diamonds coloured blue artificially. Journal of Gemmology, Vol. 7, No. 8, pp. 291-293.

Dean P.J., Lightowlers E.C., Wight D.R. (1965) Intrinsic and extrinsic recombination radiation from natural and synthetic aluminium-doped diamond. Physical Review, Vol. 140, No. 1A, pp. A353-A386.

Dyer H.B., Wedepohl P.T. (1956) Electrical measurements on type IIb diamonds. Proceedings of the Physical Society, London, Section B, Vol. 69, pp. 410-412.

Federman D. (1989) Gem profile: Fancy blue diamonds-Rarer than pink. Modern Jeweler, Vol. 88, No. 10, p. A20.

Federman D. (1998) Gem profile: Blue Heart diamond. Modern Jeweler, Vol. 97, No. 12, pp. 21-22.

Fritsch E., Scarratt K. (1992) Natural-color, nonconductive grayto-blue diamonds. Gems ↔ Gemology, Vol. 28, No. 1, pp. 35-42.

Fritsch E., Shigley J.E. (1991) Optical properties of some naturalcolor and laboratory-irradiated green to blue diamonds. In $\mathrm{R}$. Messier, J.T. Glass, J.E. Butler, and R. Roy, Eds., Proceedings of the Second International Conference-New Diamond Science and Technology, Washington DC, September 23-27, 1990; Materials Research Society, Pittsburgh, Pennsylvania, pp. 677-681

GIA Diamond Dictionary, 3rd ed. (1993) Gemological Institute of America, Santa Monica, CA.

Important Diamond Auction Results (1997) De Beers Polished Division, London, $49 \mathrm{pp}$.

Harris J.W. (1972) Black material on mineral inclusions and in internal fracture planes in diamonds. Contributions to Mineralogy and Petrology, Vol. 35, pp. 22-23.

Harris J.W., Vance E.R. (1972) Induced graphitisation around crystalline inclusions in diamonds. Contributions to Mineralogy and Petrology, Vol. 35, pp. 227-234.

Hofer S.C. (1998) Collecting and Classifying Colored Diamonds: An Illustrated Study of the Aurora Collection. Ashland Press, New York, 742 pp.
Janse A.J.A. (1995) A history of diamond sources in Africa, Part I Gems e) Gemology, Vol. 31, No. 4, pp. 228-255.

King J.M., Moses T.M., Shigley J.E., Liu Y. (1994) Color grading of colored diamonds in the GIA Gem Trade Laboratory. Gems (4) Gemology, Vol. 30, No. 4, pp. 220-242.

Klein P.B., Crossfield M.D., Freitas J.A. Jr., Collins A.T. (1995) Donor-acceptor pair recombination in synthetic type IIb semiconducting diamond. Physical Review B, Vol. 51, No. 15, pp. 9634-9642.

Krashes L.S. (1993) Harry Winston, the Ultimate Jeweler, 4th ed. Harry Winston Inc., New York, and the Gemological Institute of America, Santa Monica, CA

Leivo W.J., Smoluchowski R. (1955) A semiconducting diamond. Bulletin of the American Physical Society, Vol. 30, No. 2, p. 9.

Liddicoat R.T. Jr. (1987) Handbook of Gem Identification, 12th ed.. Gemological Institute of America, Santa Monica, CA.

Lightowlers E.C., Collins A.T. (1966) Electrical-transport measurements on synthetic diamond. Physics Review, Vol. 151, No. 2, pp. 685-688.

Lightowlers E.C., Collins A.T. (1976) Determination of boron in natural semiconducting diamond by prompt particle nuclear microanalysis and Schottky barrier differential-capacitance measurements. Journal of Physics D (Applied Physics), Vol. 9, pp. 951-963.

Meyer H.O.A., Tsai H. (1976) The nature and significance of mineral inclusions in natural diamonds: A review. Minerals Science and Engineering, Vol. 8, No. 4, pp. 242-261.

Orloff Yu.O. (1977) The Mineralogy of the Diamond. John Wiley \& Sons, New York.

Robertson R., Fox J.J., Martin A.E. (1934) Two types of diamond. Philosophical Transactions of the Royal Society of London, Vol. A232, London, pp. 463-535.

Scalisi P., Cook D. (1983) Classic Mineral Localities of the World-Asia and Australia. Van Nostrand Reinhold, New York, $226 \mathrm{pp}$.

Scarratt K. (1987) Notes from the laboratory-10. Journal of Gemmology, Vol. 20, No. 6, pp. 358-361.

Schulke A.A. (1962) Artificial coloration of diamonds. Gems et) Gemology, Vol. 10, No. 8, pp. 227-241.

Shigley J.E., Fritsch E., Reinitz I., Moses T.M. (1995) A chart for the separation of natural and synthetic diamonds. Gems 4 Gemology, Vol. 31, No. 4, pp. 256-264.

Smith S.D., Taylor W. (1962) Optical phonon effects in the infrared spectrum of acceptor centres in semiconducting diamond. Proceedings of the Physical Society, London, Vol. 79, No. 512, pp. 1142-1153.

Spencer L.K., Dikinis S.D., Keller P.C., Kane R.E. (1988) The diamond deposits of Kalimantan, Borneo. Gems « Gemology, Vol. 24, No. 2, pp. 67-80.

Tavernier J.-B. (1676) Travels in India. Translated into English by V. Ball, published in two volumes in 1977 by Oriental Books Reprint Corp., New Delhi, India.

Tillander H. (1975) The "Hope" diamond and its lineage. International Gemmological Conference, Smithsonian Institution, Washington DC, October 1975.

Watanabe K., Lawson S.C., Isoya J., Kanda H., Sato Y. (1997) Phosphorescence in high-pressure synthetic diamond. Diamond and Related Materials, Vol. 6, pp. 99-106.

Webster R. (1994) Gems: Their Sources, Descriptions, and Identification, 5th ed. Rev. by P.G. Read, ButterworthHeinemann, Oxford.

Wedepohl P.T. (1957) Electrical and optical properties of type IIb diamonds. Proceedings of the Physical Society, London, Section B, Vol. 70, pp. 177-185.

Wentorf R.H., Jr., Bovenkerk H.P. (1962) Preparation of semiconducting diamond. Journal of Chemical Physics, Vol. 36, No. 8, pp. 1987-1990.

World Diamond Industry Directory « Yearbook 1997/98, 3rd ed. (1998) CRU Publishing, London, pp. 51-56. 